\title{
Interpretation of hyperspectral remote-sensing imagery by spectrum matching and look-up tables
}

\author{
Curtis D. Mobley, Lydia K. Sundman, Curtiss O. Davis, Jeffrey H. Bowles, \\ Trijntje Valerie Downes, Robert A. Leathers, Marcos J. Montes, William Paul Bissett, \\ David D. R. Kohler, Ruth Pamela Reid, Eric M. Louchard, and Arthur Gleason
}

\begin{abstract}
A spectrum-matching and look-up-table (LUT) methodology has been developed and evaluated to extract environmental information from remotely sensed hyperspectral imagery. The LUT methodology works as follows. First, a database of remote-sensing reflectance $\left(R_{\mathrm{rs}}\right)$ spectra corresponding to various water depths, bottom reflectance spectra, and water-column inherent optical properties (IOPs) is constructed using a special version of the HydroLight radiative transfer numerical model. Second, the measured $R_{\mathrm{rs}}$ spectrum for a particular image pixel is compared with each spectrum in the database, and the closest match to the image spectrum is found using a least-squares minimization. The environmental conditions in nature are then assumed to be the same as the input conditions that generated the closest matching HydroLight-generated database spectrum. The LUT methodology has been evaluated by application to an Ocean Portable Hyperspectral Imaging Low-Light Spectrometer image acquired near Lee Stocking Island, Bahamas, on 17 May 2000. The LUT-retrieved bottom depths were on average within 5\% and $0.5 \mathrm{~m}$ of independently obtained acoustic depths. The LUT-retrieved bottom classification was in qualitative agreement with diver and video spot classification of bottom types, and the LUT-retrieved IOPs were consistent with IOPs measured at nearby times and locations. (C) 2005 Optical Society of America OCIS codes: $\quad 010.4450,280.0280$.
\end{abstract}

\section{Introduction}

Recent years have seen much interest in the development of hyperspectral imagers and in the analysis of hyperspectral imagery of optically shallow waters. Sensors include the Airborne Visible and InfraRed Imaging Spectrometer (AVIRIS), the Ocean Portable Hyperspectral Imager for Low-Light Spectroscopy (PHILLS), the Compact Airborne Spectrometer Imager, the Advanced Airborne Hyperspectral Imaging System, the Hyperspectral Mapper, and the satellite-

C. D. Mobley (curtis.mobley@sequoiasci.com) and L. K. Sundman are with Sequoia Scientific, Incorporated, 2700 Richards Road, Suite 109, Bellevue, Washington 98005. C. O. Davis, J. H. Bowles, T. V. Downes, R. A. Leathers, and M. J. Montes are with the U.S. Naval Research Laboratory, 4555 Overlook Avenue, S. W., Washington, D.C. 20375. W. P. Bissett and D. D. R. Kohler are with the Florida Environmental Research Institute, 4807 Bayshore Boulevard, Suite 101, Tampa, Florida 33611. R. P. Reid, E. M. Louchard, and A. Gleason are with the Rosenstiel School of Marine and Atmospheric Science, University of Miami, 4600 Rickenbacker Causeway, Miami, Florida 33149.

Received 11 March 2004; accepted 13 December 2004.

0003-6935/05/173576- $17 \$ 15.00 / 0$

(C) 2005 Optical Society of America borne Hyperion imager. Lee and Carder $^{1}$ analyzed the effect of spectral-band number on the retrieval of water column and bottom properties from ocean color data and found a significant advantage to using hyperspectral data when the bottom was visible in the image.

Applications of hyperspectral imagery have been quite varied. Hochberg and Atkinson ${ }^{2}$ used Advanced Airborne Hyperspectral Imaging System imagery, and Andréfouët et al. ${ }^{3}$ used the Compact Airborne Spectrometer Imager for mapping and classification of benthic types into corals, algae, and sediments by fourth-derivative analysis of remotely sensed reflectance spectra. Louchard et al. ${ }^{4}$ used derivative analysis to classify carbonate sediments. Dierssen et al. ${ }^{5}$ used spectral ratios derived from Ocean PHILLS imagery of shallow Bahamian waters to extract bathymetry and bottom type; Louchard et al. ${ }^{6}$ used spectrum matching for the same purpose on the same imagery. Sandage and Holyer ${ }^{7}$ used a neural network to determine bathymetry from AVIRIS imagery of Florida waters, and Melack and Gastil ${ }^{8}$ used AVIRIS to map phytoplankton concentrations in Mono Lake, California. Lee et al. ${ }^{9}$ used an empirical model and a predictor-corrector inversion scheme to extract water 
column properties, bottom reflectance, and depth from an AVIRIS scene of Tampa Bay, Florida. In all cases, the exploitation of hyperspectral imagery for shallow waters depends on being able to extract information about water-column optical properties, bathymetry, or bottom type from remote-sensing reflectance spectra.

The remote-sensing reflectance $R_{\mathrm{rs}}$ is the ratio of the water-leaving radiance $L_{w}$ to the incident plane irradiance $E_{d}$ from the Sun and background sky; both $L_{w}$ and $E_{d}$ are evaluated just above the sea surface. In practice, $L_{w}$ must be estimated either by removing the surface-reflected radiance from the total (waterleaving plus surface-reflected) radiance measured just above the surface or by extrapolating the upwelling radiance measured below the sea surface through the surface. Regardless of how it is obtained from field measurements, $R_{\mathrm{rs}}$ is uniquely determined by the water-column inherent optical properties (IOPs, namely, the absorbing and scattering properties of the water body), the depth and bidirectional reflectance distribution function of the bottom, the Sun and sky radiance incident onto the sea surface, and the sea surface wave state. Given complete information about these environmental conditions, $R_{\mathrm{rs}}$ can be computed exactly by numerically solving the radiative transfer equation. The solution of this forward radiative transfer problem can be obtained using the HydroLight radiative transfer software package. ${ }^{10}$

The extraction of environmental information from measured reflectance spectra constitutes a radiative transfer inverse problem, which is discussed in the present paper. Inverse problems are notoriously difficult because of potential nonuniqueness problems. Although a given $R_{\mathrm{rs}}$ spectrum uniquely corresponds to a particular set of environmental conditions, errors in the measured $R_{\mathrm{rs}}$ may cause a particular $R_{\mathrm{rs}}$ spectrum to be associated with incorrect environmental conditions when $R_{\mathrm{rs}}$ is inverted to obtain information about the environment. Thus it is often necessary to constrain inverse problems so as to guide the inversion to the correct solution. Such constraints often take the form of simplifying assumptions about the underlying physical or mathematical problem, or of added environmental information.

We approach the inversion of $R_{\mathrm{rs}}$ with a spectrummatching and look-up-table (LUT) methodology designed for the simultaneous extraction of bathymetry, bottom classification, and water-column absorption and scattering properties from hyperspectral imagery. After presenting the underlying LUT ideas, we apply our methodology to the extraction of environmental information from an Ocean PHILLS image acquired on 17 May 2000 in optically shallow waters near Lee Stocking Island (LSI), Bahamas. This area has been previously studied, so acoustic bathymetry and diver and video observation of bottom type are available for comparison with the corresponding LUT-retrieved values. We evaluate both unconstrained and constrained forms of the LUT methodology.

\section{Look-up Table Methodology}

The basic idea underlying the LUT methodology to invert $R_{\mathrm{rs}}$ is simple. First, a database of $R_{\mathrm{rs}}$ spectra corresponding to various water depths, bottom reflectance spectra, water-column IOPs, sky conditions, and viewing geometries is assembled. This database is constructed using a special version of the HydroLight radiative transfer numerical model, which provides an exact solution of the unpolarized radiative transfer equation for the given input. Each HydroLight-generated $R_{\mathrm{rs}}$ spectrum in the database is tagged by indices that identify the bottom depth, bottom reflectance spectrum, water IOPs, and Sun zenith angle that were used as input to the HydroLight run. At a minimum, this database should contain $R_{\mathrm{rs}}$ spectra generated for environmental conditions close to those occurring in nature at the time and location where the image was acquired. The database also may contain spectra corresponding to environmental conditions much different from those of the image under consideration.

Second, the $R_{\mathrm{rs}}$ spectrum for a particular image pixel is compared with each spectrum in the database, and the closest match to the image spectrum is found. The environmental conditions in nature are then assumed to be the same as the input conditions that generated the closest matching HydroLightgenerated spectrum in the database.

Finally, for example, the index tag identifying which bottom reflectance spectrum was used in the closest matching HydroLight run can be used to identify the bottom type at that pixel, or to obtain other information such as the bottom reflectance at a particular wavelength. This process is repeated for each pixel in the image to generate corresponding maps of bottom depth, bottom type, or water-column IOPs.

Although spectrum-matching has a venerable history, previous applications have been to easier problems or relied on ancillary data. Laboratory or terrestrial applications do not have the confounding influence of unknown water absorption and scattering obscuring the desired information. The previous oceanographic application by Louchard et al. ${ }^{6}$ relied on ancillary measurements of the IOPs so that the water properties could be considered known. In our unconstrained analysis mode, we need make no $a$ priori assumptions about the water depth, IOPs, or bottom reflectance.

The HydroLight runs needed to generate the database are computationally expensive, but they are done only once. Searching the database to find the closest match to a given image spectrum is computationally fast, as are the table look up and generation of graphical or digital output products.

Spectrum matching is performed using a leastsquares comparison of the measured image and database spectra by

$$
\operatorname{LSQ}(i)=\sum_{j=1}^{J} w\left(\lambda_{j}\right)\left[\tilde{R}_{\mathrm{rs}}\left(i, \lambda_{j}\right)-R_{\mathrm{rs}}\left(\lambda_{j}\right)\right]^{2},
$$


where $\tilde{R}_{\mathrm{rs}}\left(i, \lambda_{j}\right)$ is the $i$ th database spectrum at wavelength band $j, R_{\mathrm{rs}}\left(\lambda_{j}\right)$ is the measured spectrum for a particular image pixel, and $w\left(\lambda_{j}\right)$ is a weighting function between 0 and 1 that can be used to weight the contribution of different wavelength bands (e.g., to discount wavelengths where the measured reflectance data are less accurate). The smallest value of the least-squares distance LSQ determines the closest database spectrum $i$ to the measured spectrum.

Equation (1) matches the spectrum magnitudes at each wavelength; the simultaneous incorporation of spectral shape information is implicit in this criterion. Other spectrum-matching criteria have been considered. For example, the spectral image processing system (Kruse, et al. ${ }^{11}$ ) minimizes the angle between the two normalized spectra in $J$-dimensional space, where $J$ is the number of wavelengths. The spectral imaging processing system matching criterion considers only the spectral shape; it regards two spectra that differ only by a multiplicative factor as being a perfect match. Although such a matching criterion is adequate for some applications, and must be used if only uncalibrated spectra are available, the spectral imaging processing system criterion makes no use of the magnitude information available in the calibrated PHILLS spectra considered here. The LUT method uses both magnitude and spectral shape information to avoid the nonuniqueness problems that often occur when oceanographic information is extracted from uncalibrated or normalized spectra.

\section{Imagery and Ground Truth}

\section{A. Imagery}

The Ocean PHILLS airborne hyperspectral imager is a pushbroom-scanning instrument. It uses a twodimensional CCD array with 1024 cross-track pixels for spatial resolution. Light from each spatial pixel is dispersed onto the other direction of the CCD to obtain (after binning) 128 spectral channels between 400 and $1000 \mathrm{~nm}$, with a nominal bandwidth of $4.6 \mathrm{~nm}$. As normally flown, each spatial pixel is $1-2 \mathrm{~m}$ square on the ground. Davis et al. ${ }^{12}$ give detailed descriptions of the instrument design and its spectral and radiometric calibration.

Ocean PHILLS was flown during the Coastal Benthic Optical Properties field experiment in the vicinity of LSI, Bahamas during May 2000. The waters in the vicinity of LSI are generally less than $15 \mathrm{~m}$ deep, but do extend offshore to optically deep, openocean water. Nearshore waters are usually visually clear and are characterized by chlorophyll concentrations of $0.1-0.2 \mathrm{mg} \mathrm{Chl} \mathrm{m}^{-3}$. In shallow regions there is often substantially more absorption at blue wavelengths than what would be expected for Case 1 waters having the same chlorophyll concentration, because of colored dissolved organic matter (CDOM) derived from benthic biota such as seagrass and coral or sediment biofilms. Scattering, however, appears to be dominated by phytoplankton except during episodic strong winds, which can resuspend sediments.
The seabed consists of carbonate sands and harder sediments, seagrass beds, and patches of both hard and soft corals. The bottom can be uniform on scales of tens of meters, or patchy on scales of less than a meter. There are often sharp dividing lines between bottoms of different types, such as between bare sand and dense seagrass beds or coral heads.

Figure 1 shows a PHILLS image of the Adderly Cut area just to the northwest of LSI; the center of the image is at $76.121^{\circ} \mathrm{W}$ and $23.781^{\circ} \mathrm{N}$. The image was acquired at 0930 local (Eastern Daylight Saving) time (1330 Universal Time Coordinated) on 17 May 2000. After geocorrection and discarding questionable pixels at the ends of the scan lines, the usable image shown here is 900 pixels from north to south and 1425 pixels from east to west. The pixel size is approximately $1.3 \mathrm{~m}$, so the image shows an area of approximately $1.2 \mathrm{~km}$ by $1.9 \mathrm{~km}$. This image contains areas of highly reflecting ooid sands, sparse to dense seagrass beds, pavements and sediments with varying degrees of biofilm and patchy turf algae or Sargassum, and small coral patch reefs. The deepest water is $\approx 11 \mathrm{~m}$.

The PHILLS at-sensor radiances were atmospherically corrected by use of TAFKAA. ${ }^{13,14}$ Atmospheric absorption was modeled using distributions of wellmixed gases appropriate for a tropical atmosphere. The ozone content was set to $0.3 \mathrm{~atm}-\mathrm{cm}$ (300 Dobson units), and the water-vapor content was set to $3.5 \mathrm{~cm}$ of precipitable water. A maritime aerosol with a relative humidity of $90 \%$ was used; the optical properties of such an aerosol are described in Shettle and Fenn. ${ }^{15}$ The aerosol optical depth was 0.1 at $550 \mathrm{~nm}$. TAFKAA uses the wind speed to set the reflectivity of the sea surface by the surface slope statistics; the available speeds are 2,6 , and $10 \mathrm{~m} \mathrm{~s}^{-1}$. A value of $6 \mathrm{~m} \mathrm{~s}^{-1}$ tended to overcorrect for atmospheric effects, thereby occasionally giving negative radiances at the sea surface. Therefore a speed of $2 \mathrm{~m} \mathrm{~s}^{-1}$ was used, which may have led to undercorrection, i.e., to waterleaving radiances that were too large.

Given an accurate radiometric calibration and using TAFKAA in its aerosol determination mode (i.e., aerosols are chosen based on the assumption that the water-leaving radiance at several near-infrared and short-wavelength infrared wavelengths is 0 ), TAFKAA's LUT grid gives water-leaving radiances that are accurate to the equivalence of $\pm 0.003 \mathrm{sr}^{-1}$ in $R_{\mathrm{rs}}$. However, the errors will increase if, for example, the true aerosol is not closely matched by the modeled aerosol, or if swells are present in the image (i.e., the true sea surface geometry is different than the modeled slope statistics in TAFKAA). For the present image, the aerosols were input to TAFKAA rather than being determined from the near-infrared and short-wavelength infrared wavelengths. Likewise, the calibration processing was fairly involved. ${ }^{16}$ Both of these situations may lead to larger systematic errors in the final $R_{\mathrm{rs}}$.

Inspection of the PHILLS spectra show that they indeed do not approach zero for wavelengths beyond $700 \mathrm{~nm}$, as would be expected for bottom depths of 


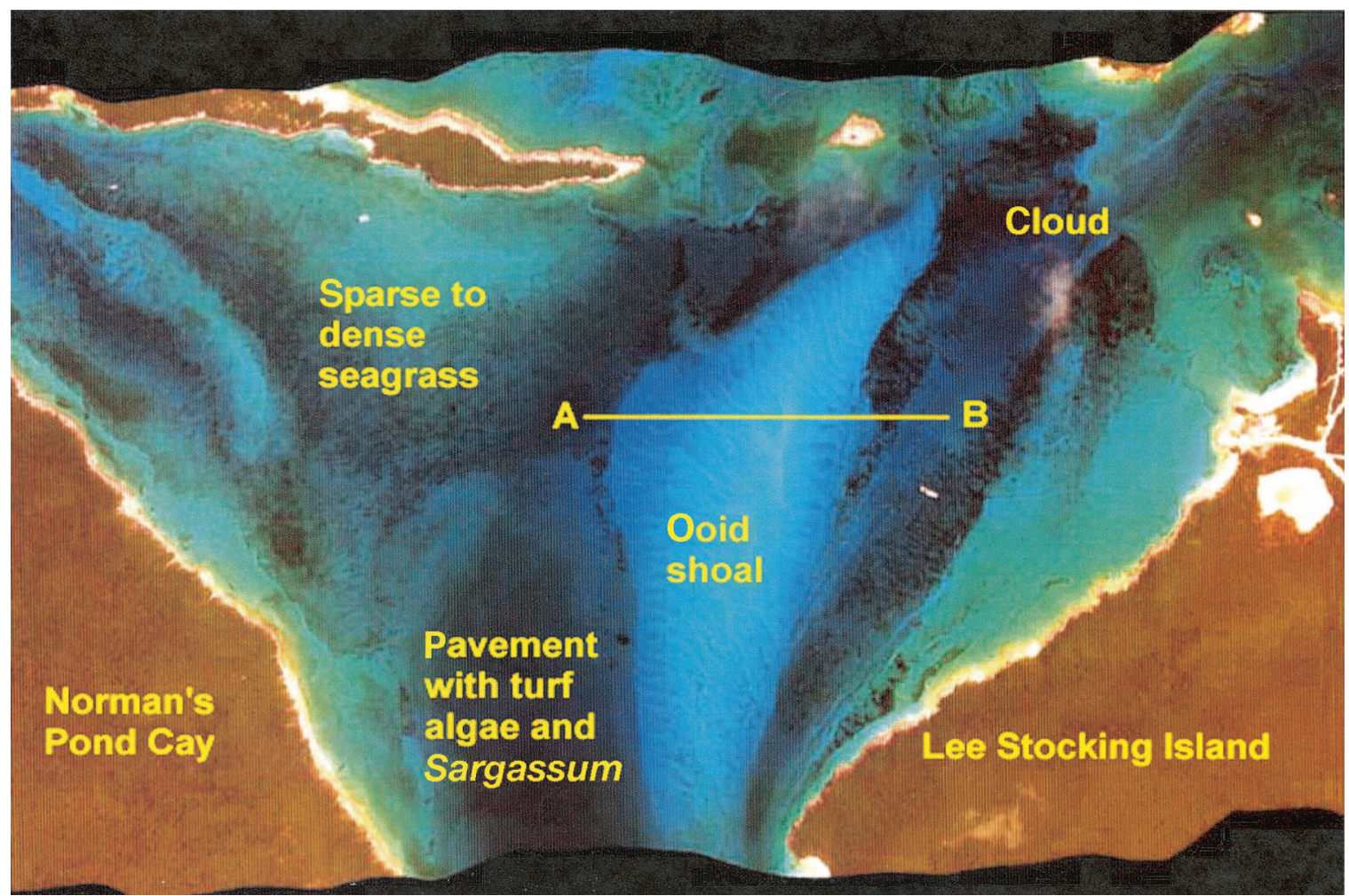

Fig. 1. Image of Adderly Cut generated from wavelengths 446, 565, and $680 \mathrm{~nm}$ of the hyperspectral PHILLS data. Major features are identified. Line A to B is the west-to-east transect plotted in Fig. 3.

more than a meter. All of the database $R_{\mathrm{rs}}$ spectra for bottom depths of $1 \mathrm{~m}$ or more are essentially zero beyond $750 \mathrm{~nm}$. Dierssen et al. ${ }^{5}$ compared data from the same PHILLS instrument at a nearby location with ground-truth $R_{\mathrm{rs}}$ spectra measured by a hyperspectral tethered spectral radiometer buoy (HyperTSRB). ${ }^{17}$ They concluded that the 2000 version of the PHILLS instrument gave spectra that were too high in the red and were also too high over most of the spectrum for areas of seagrass bottoms. Kohler ${ }^{18}$ compared PHILLS spectra from the 1999 version of this instrument with Hyper-TSRB data and found that both an offset and a gain were necessary to bring the PHILLS spectra into agreement with the HyperTSRB spectra. Louchard et al. , $^{4,6}$ also adjusted spectra from the 1999 version of the PHILLS instrument by subtracting the difference of a deep-water PHILLS spectrum and a HydroLight-computed spectrum for infinitely deep water from each shallow-water spectrum. We thus hypothesize that our PHILLS spectra are systematically too large, which is consistent with an undercorrection of atmospheric effects caused by using a $2 \mathrm{~m} \mathrm{~s}^{-1}$ wind speed in TAFKAA. Lacking extensive ground-truth $R_{\mathrm{rs}}$ data, we cannot say if the offsets beyond $700 \mathrm{~nm}$ also occur down to $400 \mathrm{~nm}$ or if the offset is the same for every wavelength. Nevertheless, we can attempt to correct for any systematic, wavelength-independent bias by shifting each PHILLS spectrum so that its minimum value, which is generally located somewhere beyond $650 \mathrm{~nm}$, is zero. We made this offset to zero for each spectrum before performing the spectrum matching.

\section{B. Bathymetry}

Acoustic bathymetry in the waters surrounding LSI was acquired from a small boat during 16-20 June $2001 .^{6}$ Bathymetric measurements were recorded at a repetition rate of $0.7 \mathrm{~Hz}$ using a Suzuki ES2025 echo sounder, and each depth was recorded along with its time and the latitude and longitude as determined by the Wide Area Augmentation System global positioning system (GPS). The acoustic data were corrected to mean sea level to account for tide differences. Extracting only the acoustic data that fell within the latitude-longitude bounds of the Adderly Cut image of Fig. 1 left 98,751 depths. The GPS latitude-longitude coordinates were converted to Universal Time Coordinated and then to image pixel coordinates. Because of the slow boat speed and fast sample rate, a given PHILLS pixel often contained several acoustic depths. Multiple acoustic depths within any PHILLS pixel were averaged to get the depth for that pixel. The final result was 20,446 image pixels for which an acoustic depth is available. These pixels are shown by the black boat track in Fig. 2 . The depth contours of Fig. 2 were generated by interpolation of the available acoustic depth values using the Interactive Display Language ${ }^{19}$ contouring routine with smoothing by an 11-pixel boxcar filter ( \pm 5 pixels to either side of a given pixel). 

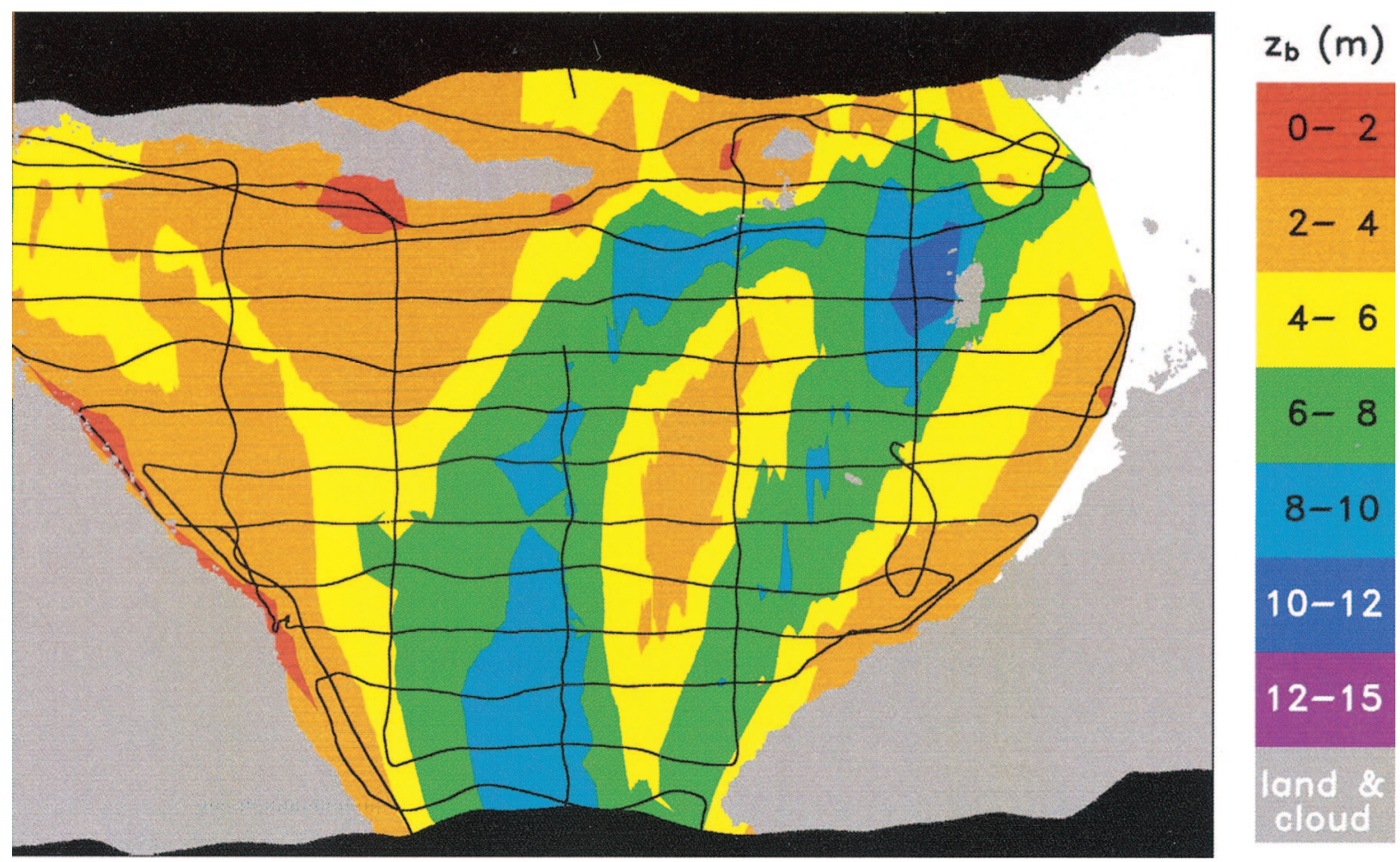

Fig. 2. Bathymetry corresponding to the area shown in Fig. 1. The black line shows the track of the small boat used to acquire the acoustic data.

To gain some idea of the accuracy of the tidecorrected acoustic depths, we compared the depths for all pixels where east-west and north-south boat tracks crossed. In principle, the mean sea level depths at the crossings should be the same for both tracks, which may have been hours apart. There were 120 such crossings, including acoustic data from areas not shown in Figs. 1 and 2. The average difference in the depths at the crossing points was $0.10 \mathrm{~m}$, with a standard deviation of $0.08 \mathrm{~m}$. Only ten crossings had a difference of more than $0.20 \mathrm{~m}$, and the largest difference was $0.27 \mathrm{~m}$. There was no correlation between the bottom depth and the difference in the depths of the crossing tracks. Thus we believe that the acoustic depths are accurate to within $0.1-0.2 \mathrm{~m}$ for depths of 2-12 $\mathrm{m}$.

\section{Geocorrection and Global Positioning System Errors}

The PHILLS image was geocorrected by comparison of 379 ground control points (for the entire flight line, which extended beyond the Adderly Cut area) as seen on the raw PHILLS image and on an IKONOS image, which covered the Adderly Cut area at a $2 \mathrm{~m}$ resolution. Performing georectification with image warping can lead to significant errors. During the warping, the GPS locations of all other points in the image are inferred from the known points. The errors occur when there are only a limited number of known ground control points or the points are not distributed across the image but instead cover only a small area of the image. In the present case, after rubbersheeting, the rms error for these points was $3.1 \mathrm{~m}$.
To gain some idea of the magnitude of the horizontal position errors due both to errors in the GPS positioning of the acoustic bathymetry and to the warping of the PHILLS image, we plotted the acoustic depths along the transect from A to B of Fig. 1 along with the magnitude of the corresponding PHILLS spectra at selected wavelengths. The result can be seen in Fig. 3. Because the reflectance of the ooid sand in this shoal area is probably uniform, it is reasonable to assume that the shallowest acoustic depth along the transect from A to B corresponds to the highest magnitude of $R_{\mathrm{rs}}$. We thus associate the shallowest acoustic depth and the highest $R_{\mathrm{rs}}$ values as indicated by the dashed lines in Fig. 3. There is an offset of 17 pixels between the minimum acoustic

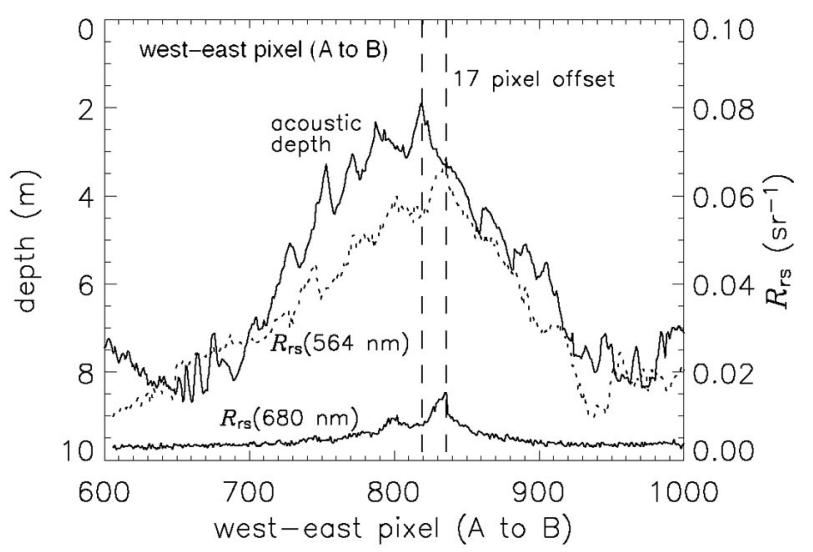

Fig. 3. Comparison of acoustic depth and $R_{\mathrm{rs}}$ along the west-toeast transect A to B shown in Fig. 1. 
depth and the maximum $R_{\mathrm{rs}}$ values. For a pixel size of $1.3 \mathrm{~m}$, this is a discrepancy of $22 \mathrm{~m}$ on the ground. This error is larger than what might be expected from the rms error of the image warping and the expected error of roughly $5 \mathrm{~m}$ in the GPS positioning. It is more speculative to associate other peaks in the depth profile with peaks in the $R_{\mathrm{rs}}$ values, but there appear to be discrepancies of the order of ten pixels, i.e. of the order of $10 \mathrm{~m}$, when we associate the bathymetic data with the image data. These discrepancies represent the combined errors due to imperfect GPS positioning of the acoustic data, imperfect warping of the PHILLS image during geocorrection, and possible migration of the ooid sand shoal in the year between the PHILLS image and the acoustic survey.

There are few other points in the image for which an acoustic depth measurement can be reliably associated with the $R_{\mathrm{rs}}$ signal. Because the geocorrection image warping is nonlinear over the image area, it is not possible to correct horizontal mismatches in bathymetric and image data based on only a few points. We therefore conclude that, when making pixel-bypixel comparisons of the acoustic bathymetry with the PHILLS imagery, there may be horizontal positioning errors of roughly $10 \mathrm{~m}$. The depth profile of Fig. 3 shows that a horizontal mismatch of pixels by $10 \mathrm{~m}$ can correspond to an error of almost $1 \mathrm{~m}$ in the depth due to the bottom slope. Thus, although the acoustic data are accurate to 0.1 or $0.2 \mathrm{~m}$, the association of that data with a particular image pixel could be in error by as much as $1 \mathrm{~m}$, although the average error may be less.

\section{Inherent Optical Properties}

Absorption $a$ and scattering $b$ coefficients were measured with an ac-9 (Ref. 20) over part of a tidal cycle on 21 May 2000 at a location approximately $1 \mathrm{~km}$ to the northwest of the Adderly Cut area (just to the upper left of Fig. 1). Another ac-9 was used to measure the IOPs at just to the south of Adderly Cut on 1 June 1999 during the ebb tide (Ref. 6, Table 2). In both cases the ac-9 data were taken at nominal wavelengths of $412,440,488,510,532,555,650,676$, and $715 \mathrm{~nm}$, with a $20 \mathrm{~nm}$ bandwidth. These data are shown by the symbols in Fig. 4, both with and without the pure water contribution. Figure 4 also shows the $a$ and $b$ spectra as predicted by a bio-optical model for Case 1 water with a chlorophyll concentration of $0.2 \mathrm{mg} \mathrm{Chl} \mathrm{m}{ }^{-3}$.

For purposes of hyperspectral data analysis, it is necessary to extrapolate and interpolate the available ac-9 data to cover the wavelength range of the hyperspectral image. We extended the ac- 9 data to the $400-750 \mathrm{~nm}$ range, with $5 \mathrm{~nm}$ bandwidths (which we call the LUT standard wavelengths), as follows. As can be seen in Fig. 4(a), the ac-9 a spectra (without the water contribution) resemble CDOM absorption spectra, which are well described by an exponential function of wavelength. We therefore used the slope of the 412 and $440 \mathrm{~nm}$ values to define an exponential function of the wavelength characteristic

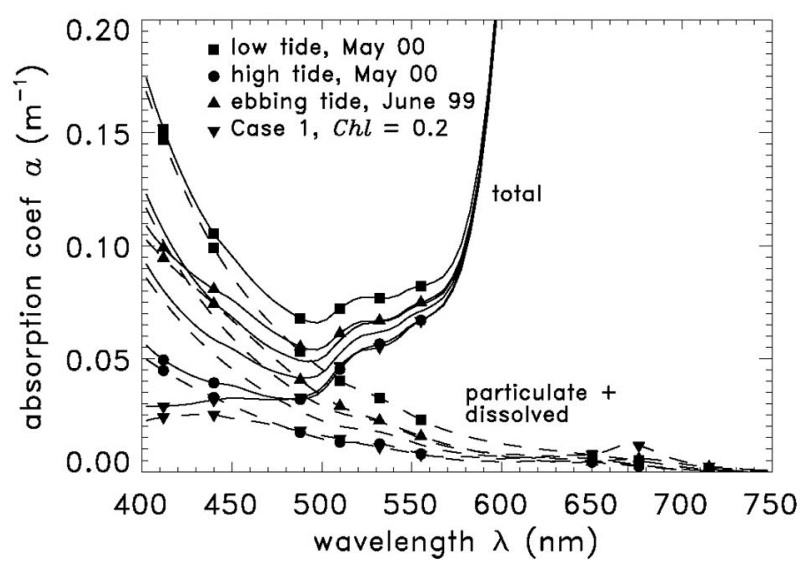

(a)

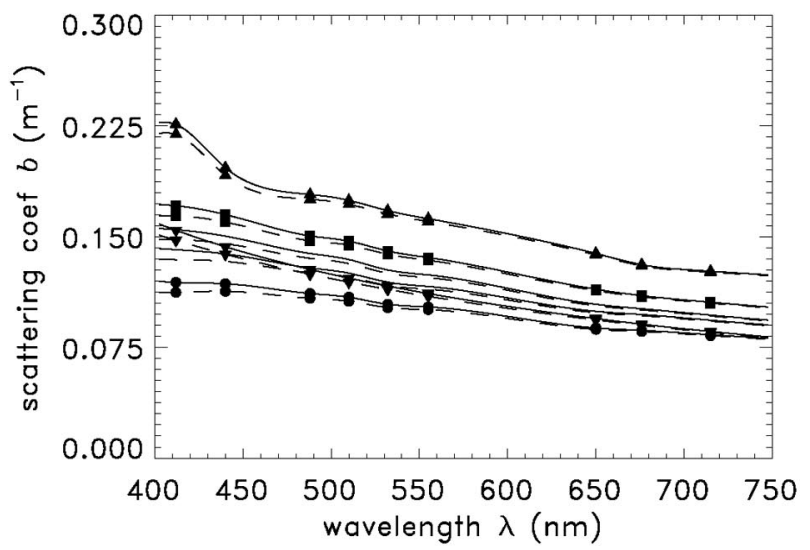

(b)

Fig. 4. Measured ac-9 (a) absorption and (b) scattering spectra. The solid curves include pure water; symbols are at the ac- 9 wavelengths.

of CDOM absorption, which was then used to define the absorption for the LUT bands centered at 402.5 and $407.5 \mathrm{~nm}$. Although not generally applicable, this extrapolation is appropriate for these CDOMdominated waters. Absorption beyond $715 \mathrm{~nm}$ was assumed to be due only to water. Values at other LUT wavelengths were obtained by cubic spline interpolation of the available ac-9 values. The ac-9 scattering coefficients were extended in a similar fashion using the available bands to define a $\lambda^{-n}$ functional form for extrapolation to 400 and $750 \mathrm{~nm}$.

The Adderly Cut area has deep, open-ocean water to the northeast and extensive shallows to the northwest and south. Strong tidal currents alternately flush the area with water from the open ocean or from the shallows. The flood tide brings in open-ocean water, which has chlorophyll concentrations near $0.2 \mathrm{mg} \mathrm{Chl} \mathrm{m}{ }^{-3}$. As can be seen in Fig. 4(a), the total absorption at high tide is very close to that for Case 1 water with $0.2 \mathrm{mg} \mathrm{Chl} \mathrm{m}^{-3}$ at wavelengths of $470 \mathrm{~nm}$ and greater. Below $470 \mathrm{~nm}$, there is additional absorption in the blue. The ebb tide drains the extensive shallow areas, which are covered by seagrass beds, corals, and ooid sands and pavements with varying degrees of biofilm. These benthic biota are a source of 
water-column CDOM that is unrelated to the phytoplankton concentration. ${ }^{21}$ The ebb tide carries this CDOM-rich water from the shallows, which greatly increases the absorption at blue wavelengths. The ebb-tide water thus has a much different absorption spectrum than Case 1 water for any chlorophyll concentration. Because of the benthic CDOM, the absorption coefficient varies by over a factor of 3 during the tidal cycle of 21 May 2000, with the highest CDOM concentration and absorption occurring at low tide. The flood-tide water from offshore appears to retain some of this CDOM, as indicated by the additional absorption in the blue noted above. The 1 June 1999 measurement, which was made on a falling tide, is consistent with those measurements of 21 May 2000.

Figure 4(b) shows the corresponding scattering coefficients $b$. The scattering coefficient for the 21 May 2000 measurements is only $\approx 30 \%$ larger at low tide than at high tide, which indicates that the ebb and flood of the tide have a smaller effect on the particulate load in the water than on the CDOM concentration. The scattering coefficient remains close to that predicted by the Case 1 model with $0.2 \mathrm{mg} \mathrm{Chl} \mathrm{m}{ }^{-3}$ throughout the tidal cycle. This implies that most of the scattering in the water column is due to phytoplankton. The 1 June 1999 scattering coefficients are somewhat higher indicating, perhaps, additional mineral particles in the water from resuspended sediments or detritus from benthic plants.

It thus appears that in this area the absorption coefficient is strongly coupled to the tidal cycle and is much greater at blue wavelengths than for Case 1 water with the same chlorophyll concentration. The scattering coefficient, on the other hand, is less variable, is weakly coupled to the tides, and is closer to what would be expected in Case 1 water. The time of the PHILLS image acquisition, 0930 Eastern Daylight Saving Time on 17 May 2000, was just after a high tide at 0847 Eastern Daylight Saving Time (the next low tide was at 1440). The period between image acquisition on 17 May and the nearby IOP measurements on 21 May was one of stable weather and no visually apparent changes in water conditions. Thus a reasonable $a$ priori guess as to the IOPs at the time of image acquisition could be made by using one of the higher-tide IOP sets from the 21 May 2000 measurements.

We also added pure water and spectra defined by the Case 1 IOP model in HydroLight for chlorophyll concentrations of $0.05,0.2$, and $0.5 \mathrm{mg} \mathrm{Chl} \mathrm{m}^{-3}$. We do not expect that these IOPs would describe the Adderly Cut waters, but their presence in the database serves as a test of the algorithm's ability to extract the correct IOPs when others are also available. To have a wider selection of spectra in the IOP database, we also interpolated between the four ac-9 spectra measured on 17 May 2000. This gives a total of four sets of measured IOPs, three sets obtained from interpolation of measurements, and four sets of modeled IOPs, for a total of 11 sets of absorption and

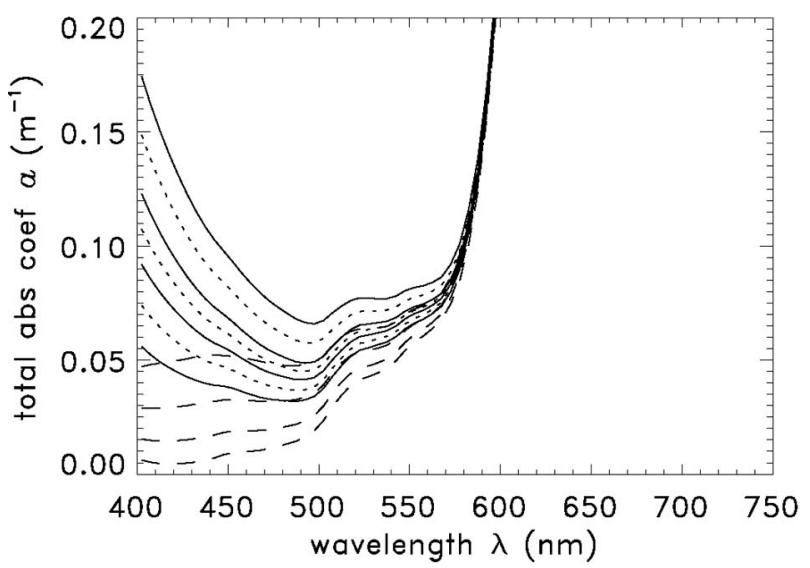

(a)

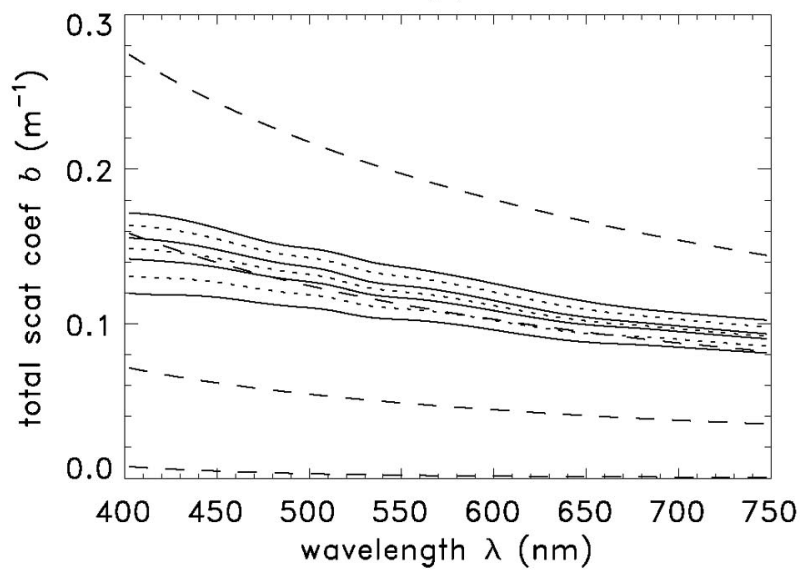

(b)

Fig. 5. Eleven total (a) absorption and (b) scattering spectra in the database. Solid curves, measured ac-9 spectra; dotted curves, interpolated ac-9 spectra; dashed curves, pure water (bottom curve) and Case 1 models.

scattering spectra in the database. These $a$ and $b$ spectra are shown in Fig. 5. Figure 5(b) shows that the Case 1 scattering spectra vary much more in magnitude as a function of chlorophyll concentration than do the measured $b$ over the course of a tidal cycle.

\section{E. Bottom Classification}

Bottom type in the Adderly Cut area has been classified by a combination of diver observation and video recorded from a small boat.6,22 As mentioned above, the bottom includes bare oolitic sand shoals in areas swept by strong tidal currents; sands stabilized by sparse to dense beds of Thalassia; pavement with varying coverages of Sargassum, turf algae, soft corals, and sponges; and small patch reefs and isolated hard coral heads. The sediments are covered by varying degrees of biofilm. Figure 6 shows the bottom classification based on video recorded from a small boat. Visual classifications such as sparse to medium seagrass or patchy Sargassum do not allow for quantitative analysis in terms such as leaf area index, but they do serve for qualitative evaluation of the LUT retrievals of bottom type. 


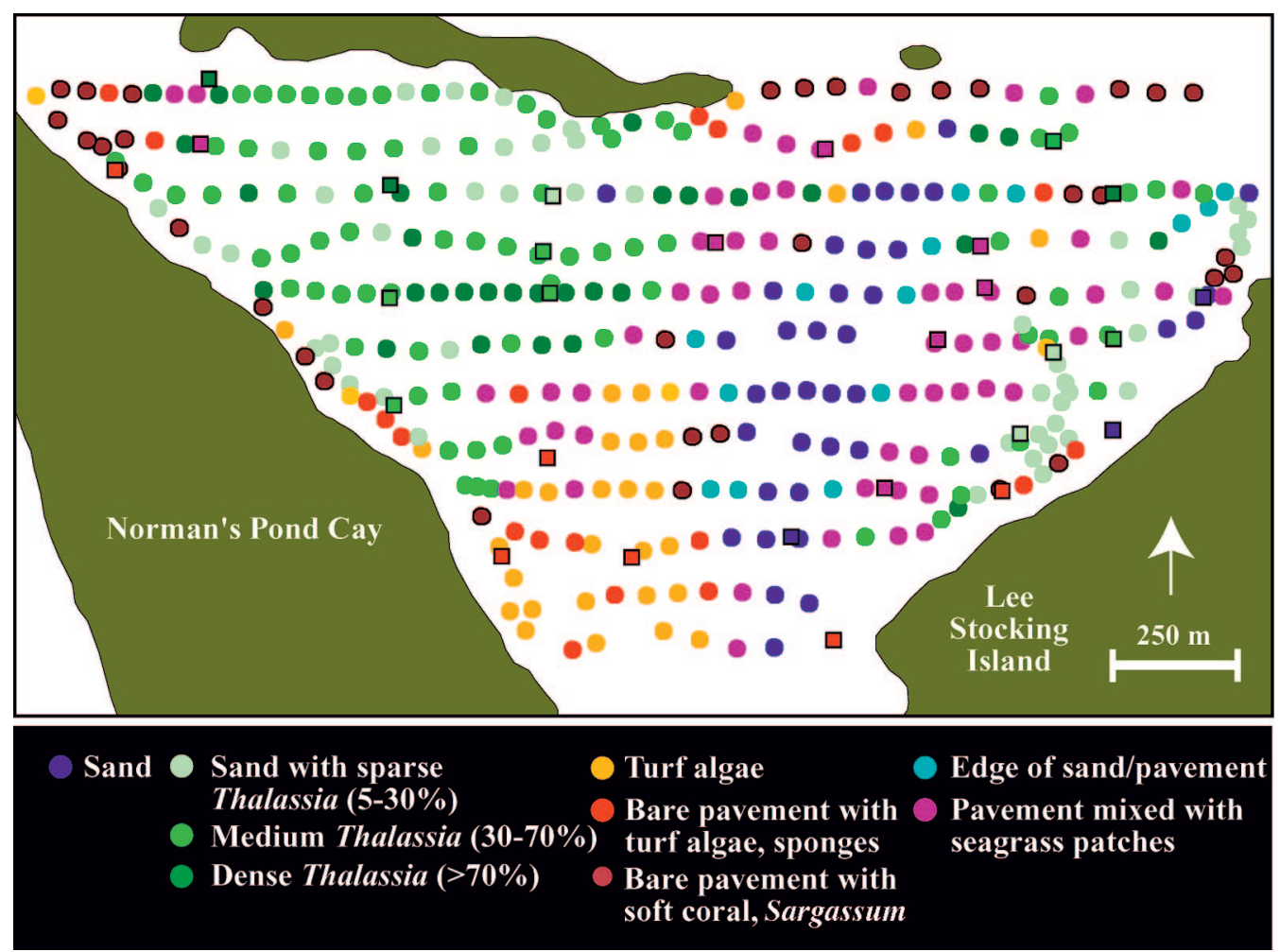

Fig. 6. Bottom classification based on diver observation (squares) and video recorded from a small boat (circles).

\section{F. Bottom Reflectance}

Spectral irradiance reflectances $R_{b}$ for various bottom materials in the LSI area have been measured both in situ with diver-operated instruments ${ }^{23,24}$ and in the laboratory on sediment cores ${ }^{25,26}$ and plant specimens ${ }^{27}$ returned from the field. In many cases the measured quantities were reflectance factors that are equated to the irradiance reflectance under the assumption that the material is a Lambertian reflector.

Selected sediment and biota reflectances are shown in Fig. 7. The spectra of Fig. 7(a) show the wide range of reflectance magnitudes occurring for sediments ranging from clean ooid sand (top spectrum), through sand with varying degrees of biofilm, to pavement, grapestone, and other dark, hard sediments (bottom spectrum). Figure 7(b) shows the reflectance spectra for selected biota including bleached coral (top spectrum), clean seagrass leaves (Thalassia), turf algae, brown seaweed (Sargassum), corals, and sponges. These spectra are in many cases averages of several spectra measured on different plants or on different parts of the same plant. There may well be other biota in the Adderly Cut area that are not represented in our reflectance database. The spectra of Figs. 7(a) and 7(b) can be combined to obtain spectra for mixtures such as sand and seagrass, or pavement and Sargassum, as may be appropriate to describe particular locations in Adderly Cut. Figure 7(c) shows such reflectance mixtures for clean seagrass leaves combined with a sand substrate measured in a seagrass bed and for mixtures of pavement with turf algae, Sargassum, and coral. The mixing was done at $10 \%$ increments, i.e., $90 \%$ sand $+10 \%$ grass, $80 \%$ sand $+20 \%$ grass. These mixtures are rather limited given the ranges of possible bottom reflectances found in nature. The coral reflectance used in the mixing was an average of several rather different reflectances for different coral species, and the Sargassum and turf algae spectra were each measurements on a single plant.

We also included three gray-bottom reflectances with wavelength-independent reflectances of $0.2,0.1$, and 0.0 (a black bottom). Although such spectra are unnatural and would not be included in a database for operational image analyses, their presence provides a test of the matching algorithm's tendency to go astray if given the chance. Including the measured end members, the mixtures, and the three gray spectra, there are 63 bottom reflectance spectra in the database. These are shown in Fig. 7(d).

\section{Database Generation}

A special version of the HydroLight 4.2 radiative transfer model (called EcoLUT) was used to create a database of $R_{\mathrm{rs}}$ spectra for evaluation of the LUT methodology. The water IOPs were assumed to be homogeneous (constant with depth). Finite-depth bottoms were assumed to have a Lambertian bidirectional reflectance distribution function characterized by the irradiance reflectances just discussed. Runs were made at the LUT standard wavelengths, namely, at the seventy $5 \mathrm{~nm}$ wavelength bands from 400 to $750 \mathrm{~nm}$. For computational efficiency, all IOPs 


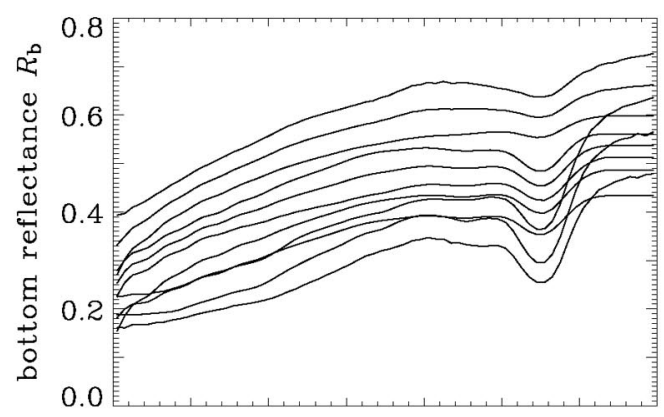

(a)

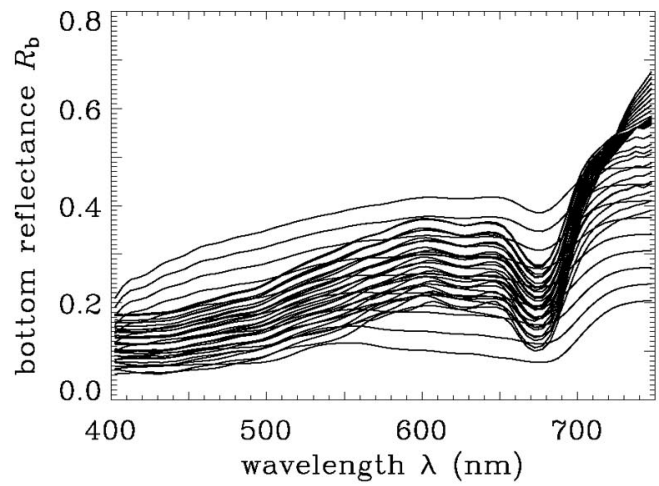

(c)

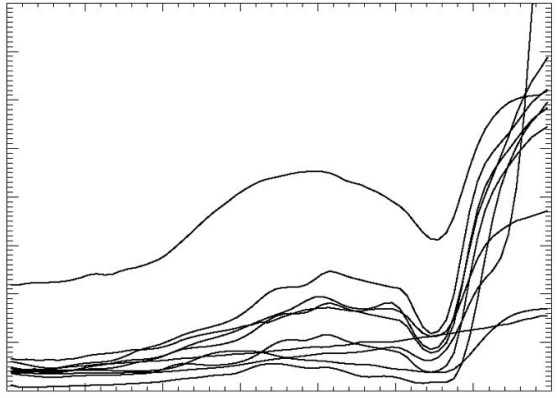

(b)

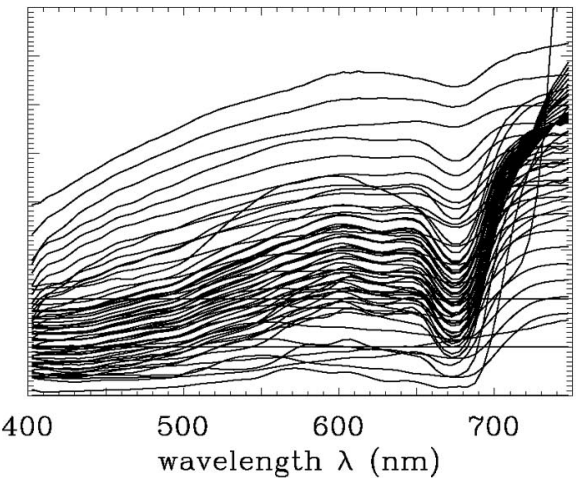

(d)

Fig. 7. Irradiance reflectances of various bottom materials and mixtures: (a) sediments, (b) biota, (c) mixtures, (d) all spectra.

and bottom reflectances were preprocessed to obtain values at the LUT standard wavelengths before being used as input to EcoLUT.

No backscatter data were available, from which it would be possible to determine the backscatter fraction from the backscatter coefficient and the scattering coefficient. It is likely that the phytoplankton had a backscatter fraction of 0.015 or less. ${ }^{28}$ However, in these clear waters, backscatter by the water itself can be a significant part of the total backscatter. Simultaneous ac-9 and HydroScat-6 (Ref. 29) measurements in the Florida Keys, which also have

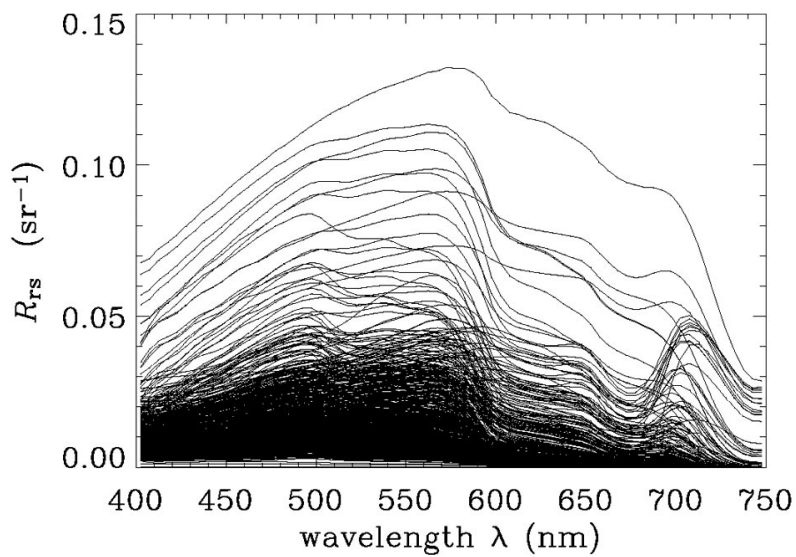

Fig. 8. Randomly chosen selection of $2 \%$ of the 41,591 EcoLUTgenerated $R_{\mathrm{rs}}$ spectra in the LUT database (832 spectra plotted). optically clear shallow water in a similar environmental setting, have shown total (particulate plus water) backscatter fractions between 0.03 and 0.04 . When processing the ac-9 data, the particle backscatter fraction was assumed to be 0.02 , which may be representative of the mixture of small mineral particles and phytoplankton suspended in the LSI waters. The resulting total backscatter fractions (including water backscatter) are in the range of 0.025-0.05, which covers the range of measurements made elsewhere in similar environments. For the database IOPs based on bio-optical models for Case 1 waters, a particle (phytoplankton) backscatter fraction of 0.005 was used. The total backscatter fraction at each wavelength was then used to generate the total scattering phase function from the Fournier-Forand family of phase functions, as described in Mobley et al. ${ }^{30}$

The bottom was placed at $0.25 \mathrm{~m}$ increments from 0.25 to $15.0 \mathrm{~m}$, for a total of 60 depths. An additional bottom option, infinitely deep water, was also included. In this case, the non-Lambertian bottom bidirectional reflectance distribution function was computed from the water-column IOPs and no separate bottom reflectance spectrum was used.

The EcoLUT runs included Raman scatter by water. However, since the IOP input to EcoLUT was the total IOPs, not chlorophyll or CDOM concentrations, fluorescence by chlorophyll and CDOM was not included in the runs. 


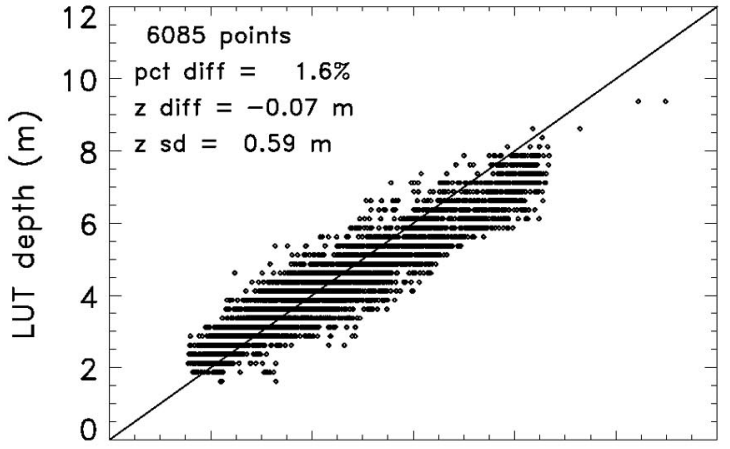

(a)

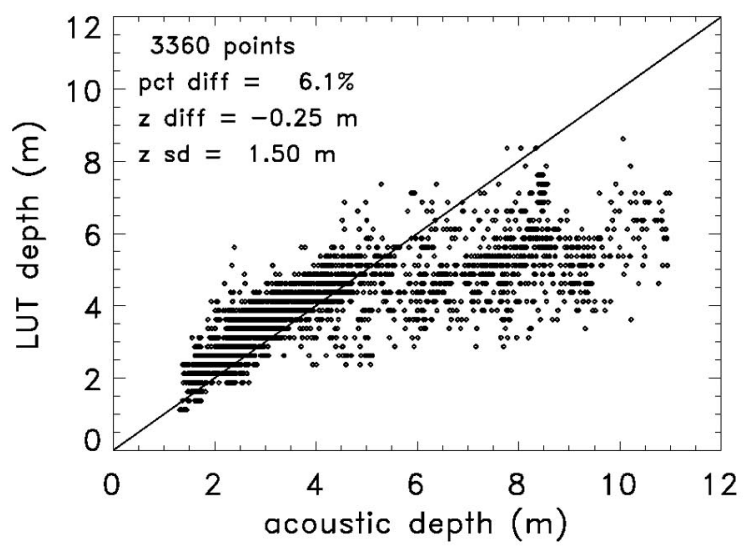

(c)

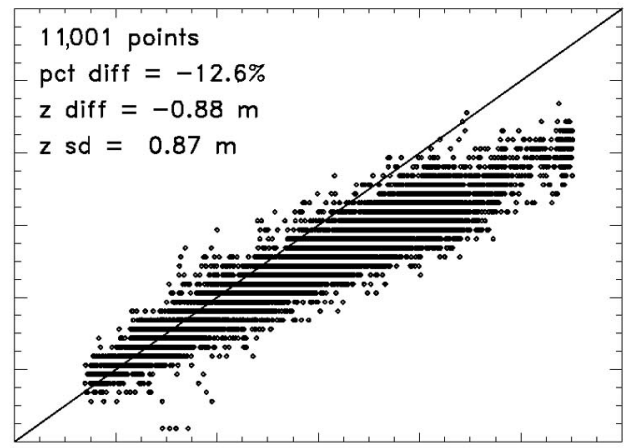

(b)

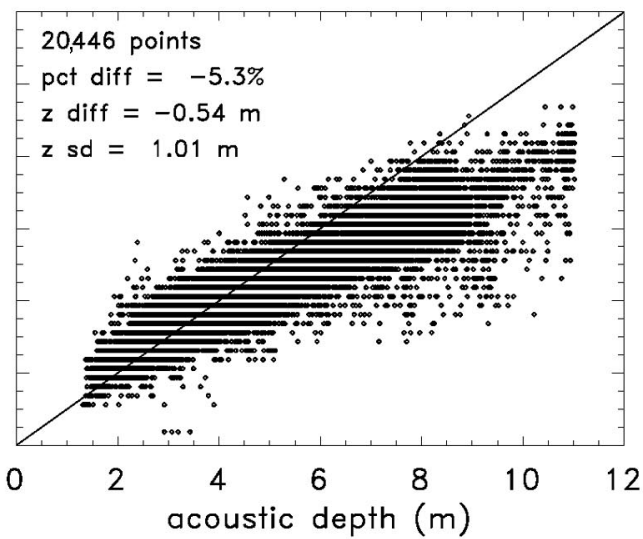

(d)

Fig. 9. Comparison of acoustic and LUT-retrieved depths as obtained using the unconstrained database. The percent difference (pct diff) and depth differences ( $z$ diff) are computed using Eqs. (2) and (3), respectively. The standard deviation of the depth differences is displayed as $z$ sd. (a) Sediments, (b) seagrass, (c) other, (d) all bottoms.

The LUT database thus has $N_{\text {IOP }}=11$ sets of IOPs, $N_{R_{b}}=63$ bottom reflectances, and $N_{z_{b}}=60$ finite bottom depths. When combined in the EcoLUT runs, these yield $N_{\text {IOP }}\left(N_{R_{b}} N_{z_{b}}+1\right)=41,591 R_{\mathrm{rs}}$ spectra for a given Sun angle, wind speed, and other external conditions. For the initial database, only one solar zenith angle was used: $\theta_{s}=60 \mathrm{deg}$, which corresponds to the Sun's location at the time of the PHILLS overflight. The sky was modeled as clear with atmospheric conditions (humidity, aerosol type, etc.) typical for tropical marine atmospheres. Only the EcoLUT nadir-viewing radiances were used to compute $R_{\mathrm{rs}}$; there are no off-nadir-viewing directions in the database. Figure 8 shows randomly selected $R_{\mathrm{rs}}$ spectra in the database.

\section{Unconstrained Inversion}

We now apply the entire EcoLUT-generated database of $R_{\mathrm{rs}}$ spectra to the analysis of the hyperspectral PHILLS data for the Adderly Cut area as shown in Fig. 1. The 72 wavelengths in the PHILLS $R_{\mathrm{rs}}$ spectra in the 400-750 $\mathrm{nm}$ range do not correspond exactly to the 70 LUT standard wavelengths. We therefore first resampled the LUT database $R_{\mathrm{rs}}$ spectra with a cubic spline fit to correspond to the 72 PHILLS wavelengths.
With the first matching we used the entire LUT database and all available wavelengths from 400 to $750 \mathrm{~nm}$, i.e., all $w\left(\lambda_{j}\right)=1$ in Eq. (1). We call this an unconstrained inversion because it uses all available database spectra and wavelengths, and no ancillary information is used. When compared with the acoustic bathymetry at the 20,446 pixels where both LUT and acoustic depths are available, the average LUT depth retrieval was $5.3 \%$ too shallow, which corresponded to the average depth being $0.54 \mathrm{~m}$ too shallow.

Figure 9 compares the LUT and acoustic depth retrievals as a function of the retrieved bottom type. The average percent difference in the LUT and acoustic depths is computed as

$$
\begin{aligned}
\text { percent difference }= & \frac{100}{N} \\
& \times \sum_{i=1}^{N} \frac{z_{b}(\mathrm{LUT} ; i)-z_{b}(\text { acoustic; } i)}{z_{b}(\text { acoustic } ; i)},
\end{aligned}
$$

where $z_{b}(\mathrm{LUT} ; i)$ is the retrieved depth at pixel $i, z_{b}$ (acoustic; $i$ ) is the acoustic depth, and $N$ is the 


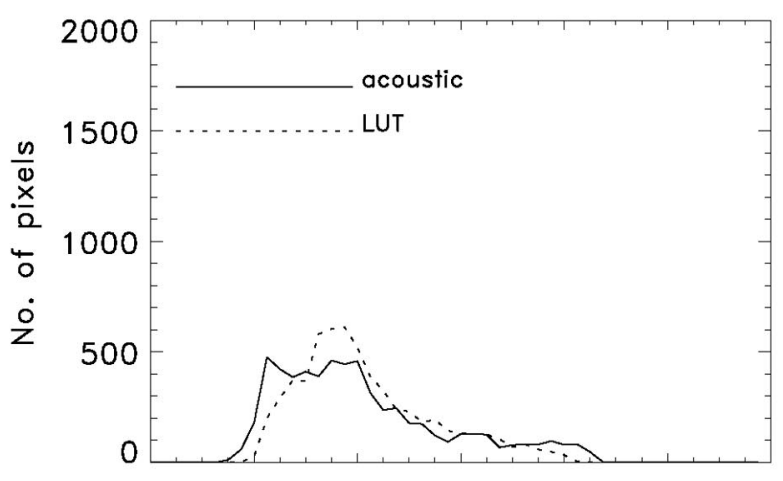

(a)

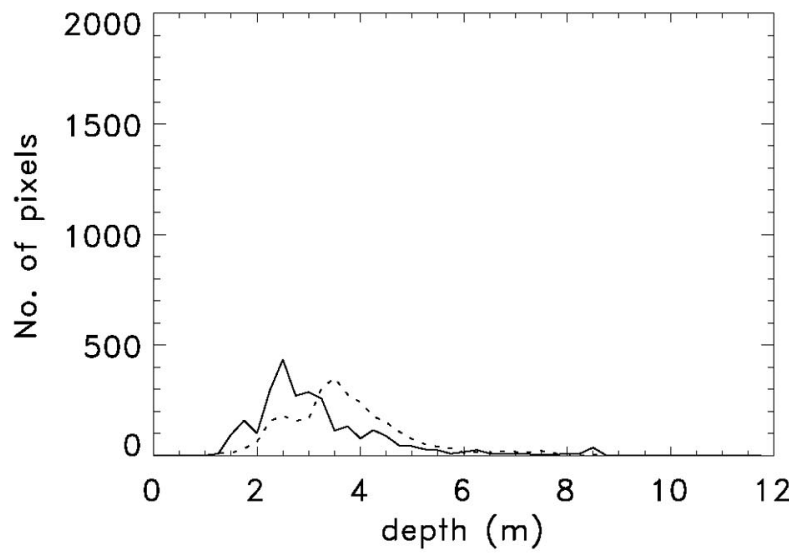

(c)

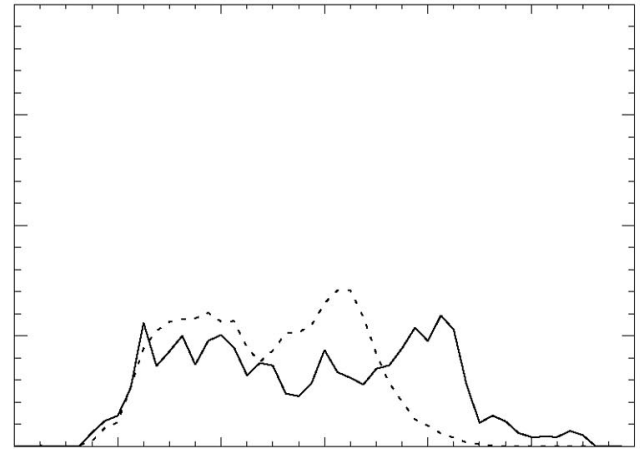

(b)

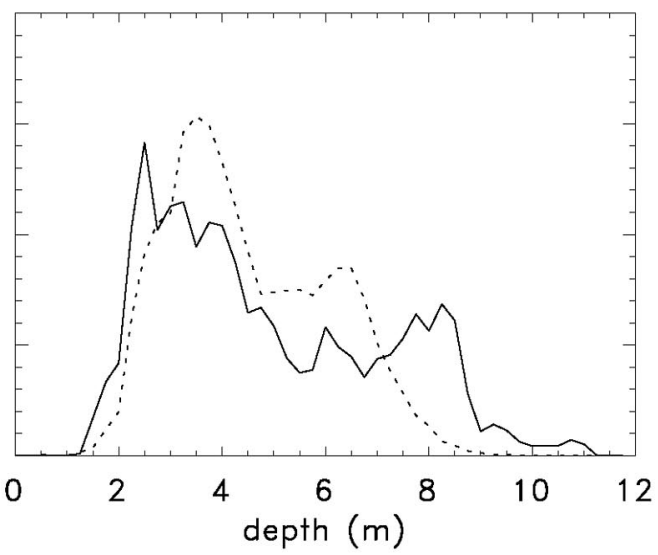

(d)

Fig. 10. Depth distribution of the number of pixels for different retrieved bottom types: (a) sediments, (b) seagrass, (c) other, (d) all bottoms.

number of pixels for a given bottom type as shown in Fig 9. The average depth difference is computed as

$$
\begin{aligned}
\text { depth difference }= & \frac{1}{N} \sum_{i=1}^{N}\left[z_{b}(\text { LUT; } i)\right. \\
& \left.-z_{b}(\text { acoustic } ; i)\right]
\end{aligned}
$$

In each case, a positive (negative) error indicates that the LUT depth is too deep (shallow). Over the sediments, which are highly reflecting and well represented in the LUT database, the average error is only $1.6 \%$, or $-0.07 \mathrm{~m}$. The depth error is larger, $-12.6 \%$ or $-0.88 \mathrm{~m}$, over the darker seagrass bottoms, which give a smaller bottom contribution to $R_{\mathrm{rs}}$ and whose reflectances in the LUT database are a mixture of an average clean-leaf seagrass reflectance and one sediment type. Thus the bottom reflectances for seagrass and sediment mixtures are perhaps not as well represented in the LUT database as are the pure sediment bottoms. There is large scatter in the depth retrievals for mixtures of coral, Sargassum, and turf algae, which are likely even less well represented in the present database. The other category also includes the gray-bottom pixels, which are always retrieved as much too shallow. The horizontal striping in the plotted points occurs because the LUT depths are at intervals of $0.25 \mathrm{~m}$.

It is not clear in Fig. 9 that most of the points cluster near the 1:1 line at the shallower depths. Therefore Fig. 10 displays the retrieved and acoustic depths as a depth distribution of the number of pixels at each depth. We note in particular that the seagrass bottoms in the 7-9 $\mathrm{m}$ depth range are not well retrieved. Figure 11 shows the pixel-by-pixel depth retrievals for the entire image. Although the LUT-retrieved depths are in increments of $0.25 \mathrm{~m}$, we binned the retrieved depths for convenient display. The qualitative agreement with the acoustic depth map of Fig. 2 is clear. No pixels were retrieved with a depth greater than $12 \mathrm{~m}$, which is correct for this area. Figure $12 \mathrm{com}$ pares the acoustic and LUT depths along transect A to B shown in Fig. 11. We can see that there is considerable pixel-to-pixel variability, but that the overall retrieval is fairly good. Moreover, we note that the average error and standard deviation between the LUT and acoustic depths are comparable to the differences that can be expected owing to GPS and geocorrection errors, as discussed above.

Figure 13 shows the pixel-by-pixel retrieved bottom type. The color-coded classification scheme is defined as follows. A pixel is flagged as sand if the 

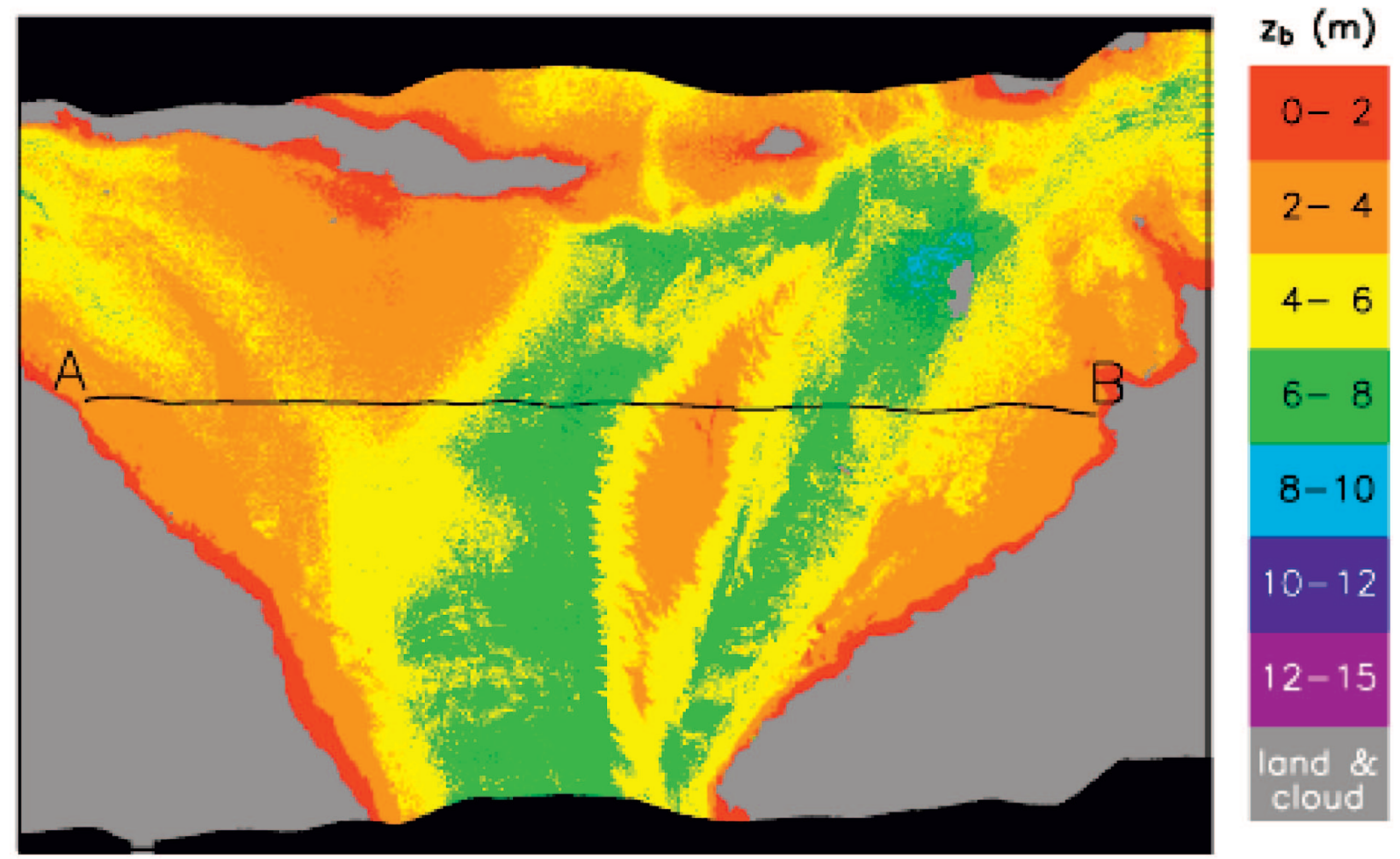

Fig. 11. Pixel-by-pixel map of LUT-retrieved depths as obtained using the offset PHILLS spectra and the unconstrained database; compare with Fig. 2. Line A to B shows the boat track used for the pixel-by-pixel comparison with acoustic depths in Fig. 12.

retrieved bottom reflectance is any of the seven database spectra for clean ooid sand to heavily biofilmed sand. These are the upper seven $R_{b}$ spectra in Fig. 7(a). Darker sediment corresponds to bottom reflectances for any of the four lower-reflectance spectra for hardpan, grapestone, or pavement. Thick grass refers to a pixel whose retrieved bottom spectrum was either the pure seagrass spectrum or a mixture of sand and grass with $60 \%$ or more grass spectrum; sparse grass is a grass-sand mixture with $10 \%-50 \%$ grass. Turf/Sarg on pvmnt flags pixels whose bottom reflectances correspond to any mixture (10\%-100\%) of the turf algae or Sargassum spectra with the pave-

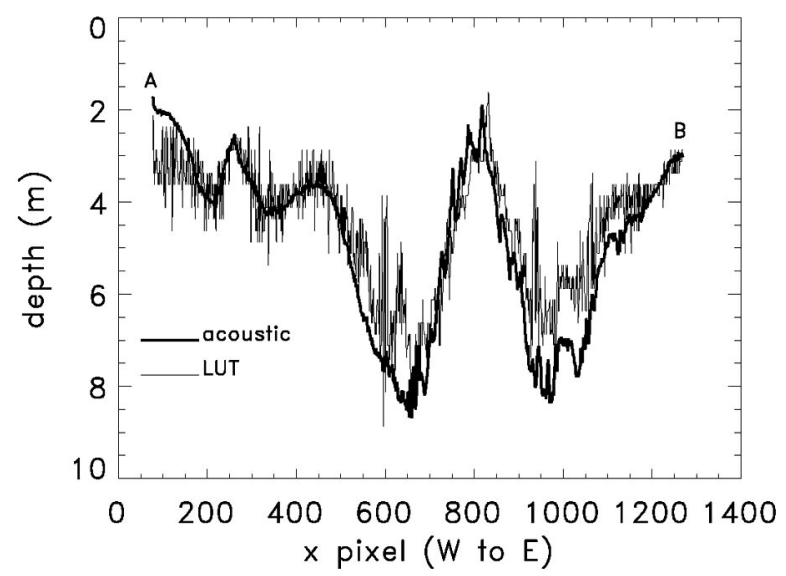

Fig. 12. Comparison of acoustic and unconstrained LUTretrieved depths along line A to B shown in Fig. 11. ment spectrum; the same selection criterion is used for coral on pvmnt. Pure biota refers to a pixel retrieved as having a reflectance spectrum for one of the seven corals and sponges in the database. Finally, gray refers to bottoms with a reflectance of $R_{b}$ $=0.0,0.1$, or 0.2 at all wavelengths. It should be remembered that our category of thick grass, for example, is based on a large contribution by the pure grass spectrum to the total bottom reflectance. This may or may not correspond to a thick-grass classification by some other scheme such as leaf area index.

With this qualitative bottom classification scheme, we can see from Figs. 13 and 6 that the LUT retrieval has done a reasonably good job of classifying areas of sediments and dense and sparse seagrass. The LUT retrieval is also consistent with an intuitive interpretation of Fig. 1. There appears to be some misidentification of seagrass versus turf or Sargassum, but this is not surprising because these reflectance spectra are dark and somewhat similar. Only $1.4 \%$ of the pixels were retrieved as pure biota; $3.7 \%$ were retrieved as a gray bottom. The curved band of turf and Sargassum near the bottom of the image parallels the edge of the PHILLS scan and is not correlated with any physical feature; note a similar band in the IOP data of Fig. 14. This band extends beyond the Adderly Cut area (on the full flight line, not shown) and indicates that these retrievals are influenced by artifacts in the PHILLS image.

Figure 14 shows the IOP retrievals color coded as to which set of IOPs was retrieved. The water IOPs 


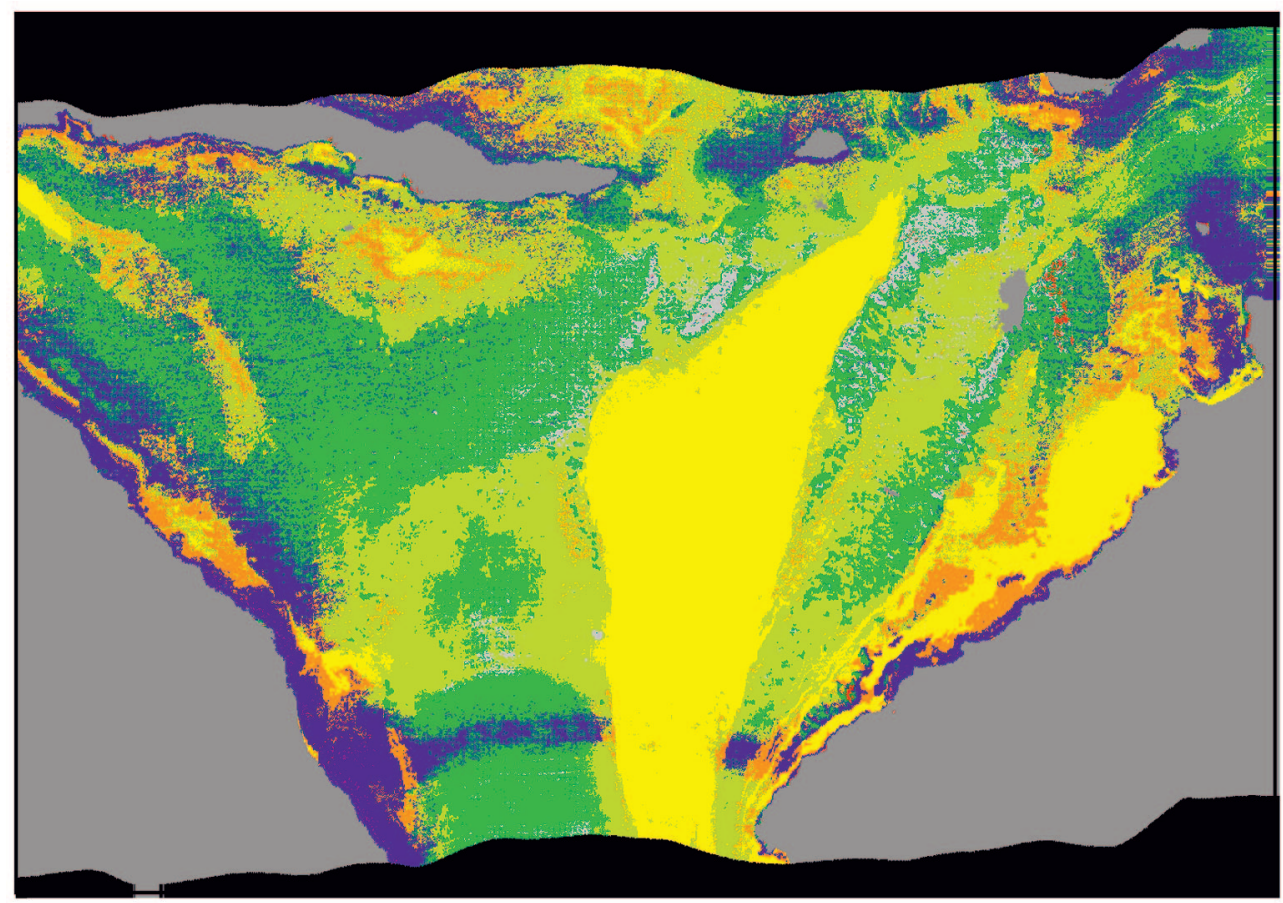

bottom
type
sand
darker
sediment
thick
grass
sparse
grass
pure
biota
turf/Sarg
on pvmnt
coral
on pvmnt
gray
land \&
cloud

Fig. 13. LUT-retrieved bottom type for the unconstrained inversion.

will have the least influence on $R_{\mathrm{rs}}$ where the bottom is brightest and shallowest, such as over the center of the ooid shoal or near the shore. The IOPs will have the greatest influence on $R_{\mathrm{rs}}$ where the bottom is darkest and deepest, such as over seagrass beds or the deeper parts of the ooid shoal. Thus the IOP retrievals are likely to be more trustworthy over the deeper and vegetated areas. These areas of Fig. 14 are predominately retrieved as IOP sets 2,3 , or 4 , which correspond to the lower-to-moderate CDOM waters that we would expect to occur just after high tide. The shallow center of the ooid shoal is retrieved
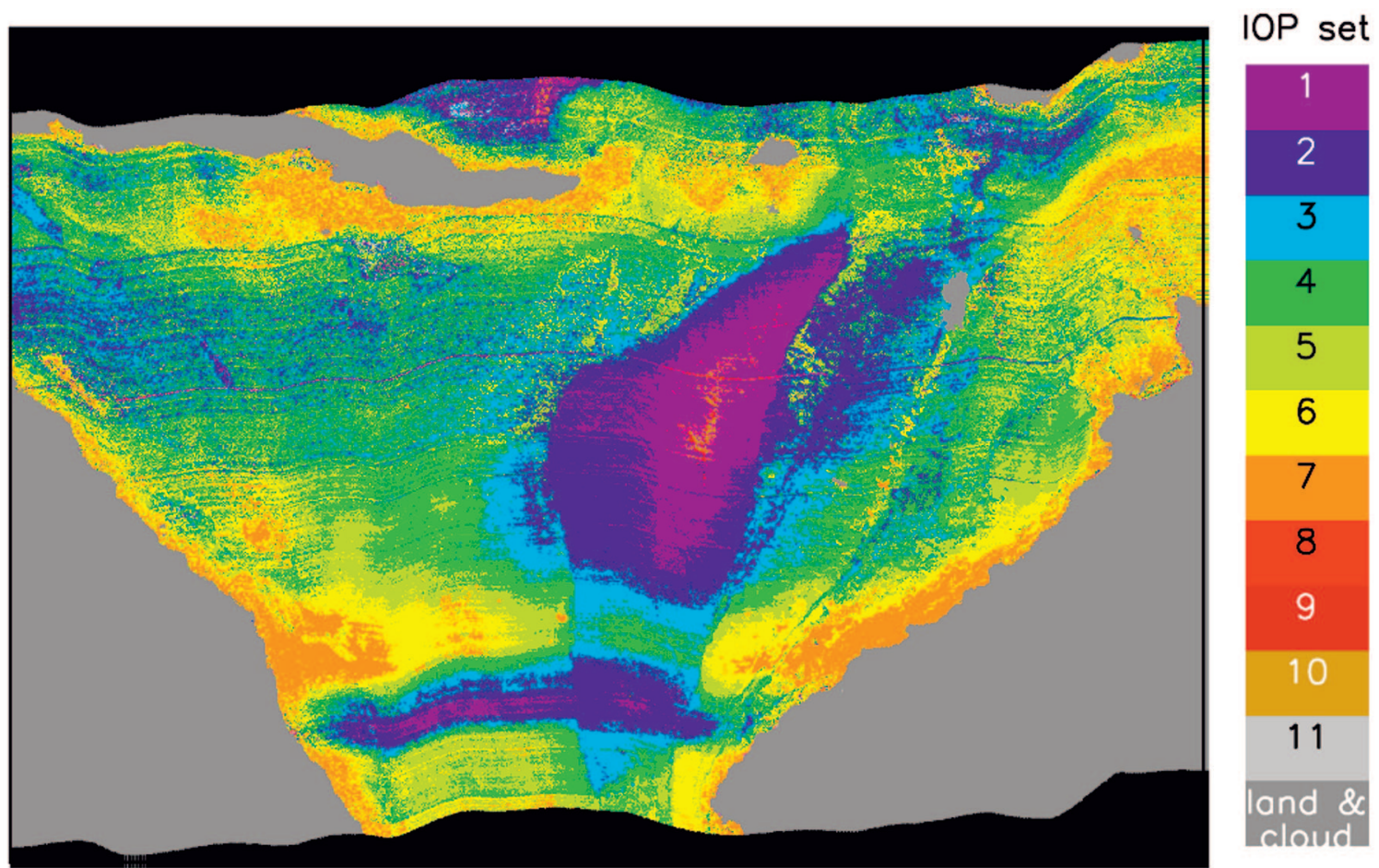

Fig. 14. LUT-retrieved IOPs corresponding to Figs. 11 and 13. IOP set 1 is the lowest-CDOM water; set 7 is the highest in CDOM. Set 8 is pure water, and $9-11$ are Case 1 waters. 
as IOP set 1 , which had the lowest CDOM concentration. We tend to discount the accuracy of this retrieval because of the shallow, bright bottom. The deeper areas of the ooid shoal are retrieved as IOP set 2 or 3 , consistent with the retrievals over the adjacent darker bottoms. The shallow nearshore regions are often retrieved as high-CDOM water. This is indeed where benthic vegetation and sediment biofilms could significantly increase the CDOM concentration during the previous slack water at high tide and where the currents are weakest and may not have mixed the waters with those of the central part of the area as the tide begins to ebb. However, those highCDOM retrievals also may be incorrect IOP retrievals resulting from inadequate representation of the corresponding bottom reflectances in the database. The sensor signal-to-noise ratio is lowest and the calibration is most difficult at blue wavelengths, which may also affect the IOP retrievals because of the strong influence of CDOM absorption near $400 \mathrm{~nm}$. Although it is not possible to decide which IOP retrievals are correct in the absence of IOP groundtruth measurements taken at the time of the PHILLS overflight, the IOP retrievals are nevertheless plausible. It is reassuring that the only pixels retrieved as Case 1 water were at the shallowest part of the ooid shoal.

\section{Constrained Inversions}

We next investigate whether the matching results can be improved by constraining the inversion. We can do this by restricting the allowed depths, bottom reflectances, or IOPs in the LUT database, or by performing the matching over a restricted wavelength interval. In all cases, it is best to be guided by the data, starting with an unconstrained inversion.

The three gray-bottom reflectance spectra were included in the initial database just to see if they ever occurred in the matching results. They seldom occur and, in any case, they are unnatural. Likewise, the IOP sets for pure water and Case 1 water were included in the database to see if they would be chosen, even though we did not expect that the Adderly Cut waters would be described by these IOPs. It was again reassuring that the matching almost never returned one of these IOP sets. Because neither the gray bottoms nor the Case 1 IOPs are found to provide frequent best matches for this image, the corresponding $R_{\mathrm{rs}}$ spectra can be omitted from the database. This gives a constrained database with 7 IOPs and $60 R_{b}$ spectra, for a total of $25,207 R_{\mathrm{rs}}$ spectra. Searching a smaller LUT database will also decrease the computer time required to process an image.

The average depth error obtained with the constrained database is $4.7 \%$, or $0.49 \mathrm{~m}$, too shallow. The various plots are visually quite similar to Figs. 9-14 and therefore are not shown. Now, however, the points of Fig. 9(c) lie nearer to the 1:1 line because there are no gray-bottom pixels. However, excluding the gray bottoms and Case 1 IOPs does not greatly improve the average retrievals because so few pixels were previously being matched with these nowexcluded values.

If we now assume that the IOP retrievals over the deeper, darker bottom regions are most likely to be correct over the entire image area, then we might improve the depth and bottom classification retrievals by reprocessing the image using only the IOPs for this retrieved range of likely values. We thus further constrained the $R_{\mathrm{rs}}$ database to include spectra corresponding only to IOP sets 2,3 , and 4 . This does indeed slightly improve the depth retrievals: The average error decreases from $-4.7 \%$ and $-0.49 \mathrm{~m}$ to $-2.2 \%$ and $-0.38 \mathrm{~m}$. This is a noticeable quantitative improvement, but the depth plots corresponding to Figs. 9-12 are visually similar to those already seen.

The regions previously retrieved as IOP set 1 are now retrieved as set 2 , which is the nearest allowed IOP set. Likewise, areas previously retrieved as highCDOM IOPs are now retrieved as IOP set 4. Although constraining the IOPs did not greatly influence the depth retrievals, the shallow nearshore areas previously retrieved as high-CDOM IOPs and as mixtures of seagrass and Sargassum or turf algae are now more often retrieved as Sargassum or turf algae, as can be seen in Fig. 15. Now 3.3\% of the pixels are retrieved as pure biota. It is not possible to say quantitatively if these changes in the bottom type retrievals are correct. However, visual comparison of Figs. 6 and 15 is good.

When the IOPs are constrained to sets $2-4$, most of the pixels are retrieved as IOP 4, except over the shallower parts of the ooid shoal. Therefore, if we assume that the entire water body is homogeneous, we can further constrain the inversion by allowing only IOP 4 in the matching. This gives almost no change in the depth or bottom-type retrievals, since most pixels were already being retrieved as IOP set 4 . In any case, constraining the dataset this much is hard to justify given our limited knowledge about the IOPs at the time of the PHILLS overflight.

We can also constrain the inversion by performing the matching using a restricted wavelength range. Since the PHILLS $R_{\mathrm{rs}}$ spectra appear somewhat noisy at wavelengths greater than $\approx 600 \mathrm{~nm}$, we performed the matching using only $400-600 \mathrm{~nm}$. In all casesunconstrained, or any of the constrained inversions discussed above-restricting the wavelength range degraded the depth retrievals. For example, for the constrained inversion with 60 bottoms and seven IOPs, the 400-750 $\mathrm{nm}$ inversion gave an average depth error of $-4.7 \%$ or $-0.49 \mathrm{~m}$, whereas the $400-600 \mathrm{~nm}$ inversion gave errors of $-10.1 \%$ and $-0.67 \mathrm{~m}$. This indicates that the wavelengths beyond $600 \mathrm{~nm}$ are contributing useful information, presumably at the shallowest depths where the bottom reflectance still contributes to $R_{\mathrm{rs}}$ and the high absorption by water makes $R_{\mathrm{rs}}$ sensitive to bottom depth.

Finally, we performed the inversion using spatially filtered PHILLS spectra. The PHILLS image was reprocessed so that the $R_{\mathrm{rs}}$ spectrum at each pixel was averaged with the eight surrounding spectra in a 3 $\times 3$ block centered on the given pixel (except at the 

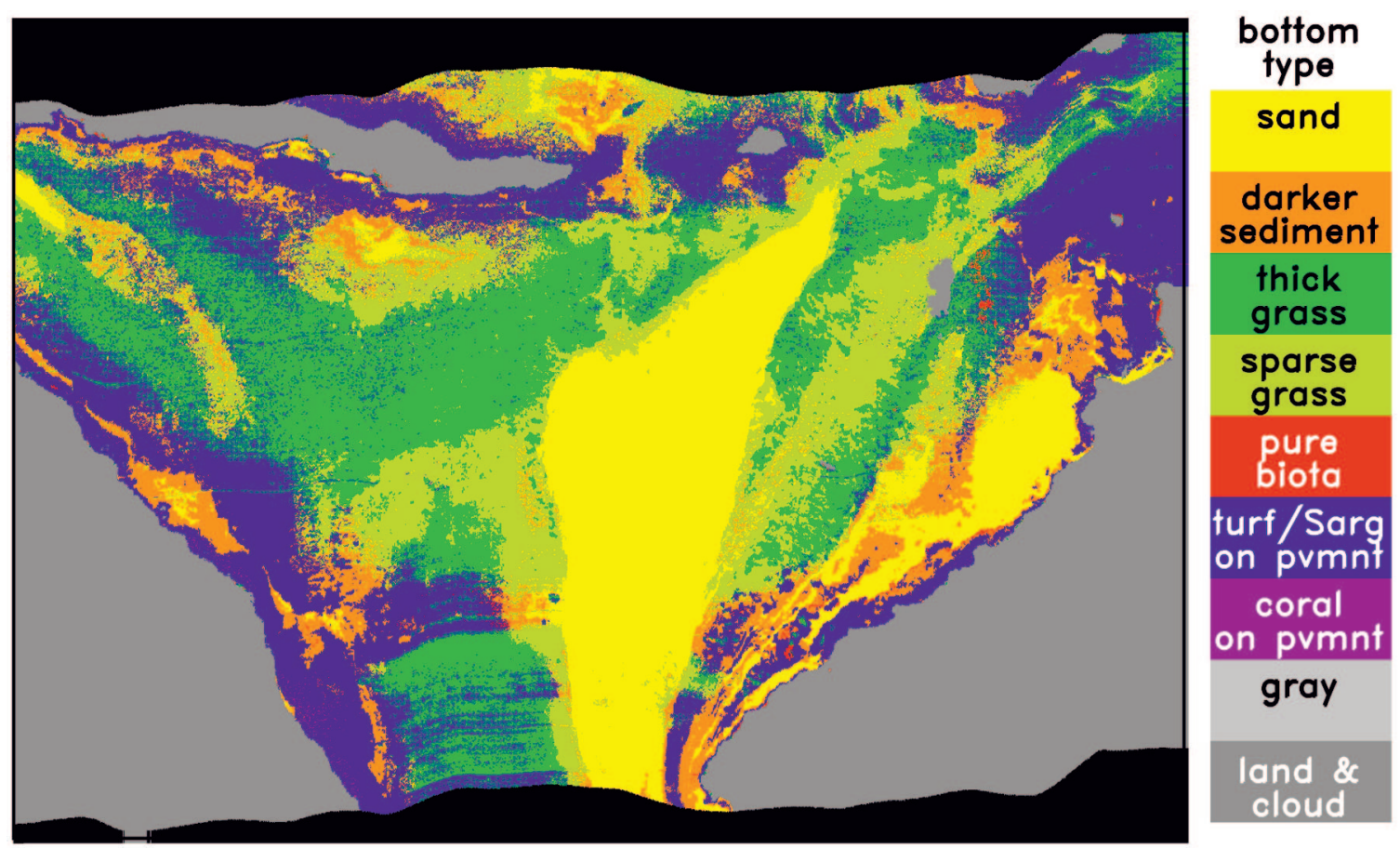

Fig. 15. Bottom type retrieval for the constrained database with only IOPs 2-4. Compare with Figs. 6 and 14 .

edges of the image, where fewer spectra were averaged). This averaging gives a slight fuzziness to the visual appearance of Fig. 1. The smoothed image, i.e., the spatially averaged PHILLS $R_{\mathrm{rs}}$, was reanalyzed using the constrained data set with 60 bottoms, IOPs $2-4$, and all wavelengths from 400 to $750 \mathrm{~nm}$. The smoothing does somewhat reduce the pixel-to-pixel variability in the depth retrievals that can be seen in Fig. 12, and the average depth error is only $-1.0 \%$ and $-0.25 \mathrm{~m}$, compared with $-2.2 \%$ and $-0.38 \mathrm{~m}$ for the same inversion applied to the unsmoothed image. The map of the retrieved bottom type is very similar to those already seen.

\section{Conclusions}

We have developed a general spectrum-matching and LUT methodology for inversion of hyperspectral oceancolor remote-sensing data. The present methodology requires no ancillary environmental information and is able simultaneously to retrieve bathymetry, bottom classification, and IOPs. It is therefore a significant improvement over previous spectrum-matching algorithms.

We evaluated our methodology by application to a PHILLS image taken near Lee Stocking Island, Bahamas. The associated database of $R_{\mathrm{rs}}$ spectra was constructed using HydroLight and the available, but limited, information on bottom reflectances and water IOPs in this area. Additional gray-bottom reflectances and IOPs for Case 1 water were included in the database to evaluate whether the LUT inversions would be led astray by the presence of spectra representing unnatural (the gray bottoms) or unlikely (the Case 1 IOPs) conditions. The LUT retrievals were validated with acoustic bathymetry and diver- and video-generated maps of bottom type.

The success of the LUT methodology depends on two requirements. First, the image $R_{\mathrm{rs}}$ spectra must be accurately calibrated. This is a difficult but is an achievable goal given recent advances in hyperspectral imaging and atmospheric correction algorithms. Poorly calibrated or relative $R_{\mathrm{rs}}$ spectra are not sufficient for accurate extraction of quantitative environmental information unless ancillary information is available to constrain the inversion. It is indeed the use of accurately calibrated $R_{\mathrm{rs}}$ spectra that avoids the nonuniqueness problems that often occur with uncalibrated spectra. Second, the database $R_{\mathrm{rs}}$ spectra used to match the image spectra must include spectra that describe the depth, bottom reflectance, and water IOPs found within the image. The database spectra can be obtained from models, as was done here, or from well-characterized field measurements. The presence of nonrepresentative $R_{\mathrm{rs}}$ spectra, which perhaps describe other locations, increases the computer time required for image processing but does not greatly degrade the retrieval in these waters with the spectra tested.

The PHILLS $R_{\mathrm{rs}}$ spectra used here appear to be systematically too large at red and longer wavelengths. Indirect evidence indicates that the offset may extend to shorter wavelengths. This is consistent with previous comparisons of PHILLS spectra with ground-truth measurements made over shallow seagrass beds. We therefore used an approximate correction for this offset by shifting each PHILLS spectrum to zero at its smallest value, which usually occurs somewhere beyond $650 \mathrm{~nm}$. 
The LUT methodology yields environmental information about bathymetry, bottom classification, and water-column IOPs that is consistent with the available ground truth. When applied in its unconstrained form, i.e., including all database $R_{\mathrm{rs}}$ spectra and wavelengths as candidates for matching the PHILLS spectra, the LUT depth retrievals were on average $\approx 5 \%$ or 0.5 too shallow when compared on a pixelby-pixel basis with the available acoustic bathymetry. This is comparable to the possible differences between the LUT and the acoustic bathymetry due to GPS errors and imperfect geocorrection of the PHILLS image (Fig. 3). However, the LUT depth retrievals do appear to be systematically too shallow by $1 \mathrm{~m}$ or more at some of the deeper locations (compare Figs. 2 and 11, or Fig. 12). The retrieved bottom type is consistent with the qualitative ground-truth map of bottom type. The retrieved IOPs are consistent with what would be expected in this area, based on nearby IOP measurements taken at other times. Few pixels were matched with either a gray bottom or Case 1 IOPs (Figs. 13 and 14), which reassuringly indicates that the spectrum-matching algorithm correctly selects the spectra for a given environment even in the presence of unrepresentative environmental conditions in the database.

Several constrained inversions were also performed. When the unnatural gray bottoms and Case 1 IOPs were eliminated from the database, the resulting depth errors decreased only slightly because the unconstrained inversion was seldom being led astray. Further constraints based on allowing only the most likely IOPs to be used in matching again gave slight increases in the accuracy of the depth retrievals. The constrained inversions gave a somewhat different map of bottom type, with seagrasssand mixtures often being replaced by mixtures of Sargassum or turf algae with pavement (compare Figs. 13 and 15). The available ground truth is not adequate for pixel-by-pixel quantitative evaluation of these retrievals, but the retrieved maps of bottom type are in all cases visually similar to the diver- and video-generated maps.

There is noticeable pixel-to-pixel variability in the retrieved bottom depths (Fig. 12). This variability decreased somewhat in the constrained inversions or when the PHILLS pixels were spatially averaged over $3 \times 3$ blocks of pixels, but in any case the variability does not obscure the overall depth retrieval.

The errors in the average depth retrieval increased somewhat when the spectrum matching was performed with only wavelengths between 400 and $600 \mathrm{~nm}$. This indicates that the wavelengths from 600 to $750 \mathrm{~nm}$ were indeed contributing useful information to the inversion and should be retained, especially when analyzing images with very shallow waters.

The success of the LUT methodology in this initial evaluation gives us reason to believe that it will prove to be a general and robust way of extracting environmental information from hyperspectral oceanographic imagery. Further improvements in the retrievals can be anticipated as additional bottom reflectance spectra and water IOPs are added to the existing database. Improved retrievals of selected information will likely be possible whenever ancillary information is available to constrain the inversions. Thus, for example, if IOP measurements are available at the time of the overflight, only those IOPs would be allowed in the spectrum matching, and the resulting retrievals of depth and bottom type likely would improve. Similarly, if bathymetric data were available, obtained either from charts or perhaps from a combined hyperspectrallidar imaging system, then the depths would be known a priori at each pixel, and the inversion would need to find only the bottom reflectance and water IOPs.

Finally, we note that the computer time required for image processing is not limiting. In the present analysis, every PHILLS spectrum was compared with every database spectrum. The unconstrained inversion of the Adderly Cut image required a few hours of time on a PC; less time was required for the constrained inversions. Thus it is reasonable that, when applied in an operational mode, maps of bathymetry, bottom classification, and water-column IOPs can be in the user's hands within $24 \mathrm{~h}$ of the PHILLS overflight. An order-of-magnitude decrease in processing time can likely be achieved by streamlining the present computer code.

This study was supported by the Environmental Optics Program of the U.S. Office of Naval Research (ONR) under contracts N00014-00-D-0161/0001 and N00014-04-C-0218 to C. D. Mobley. Collaborators W. P. Bissett and C. O. Davis were separately funded by ONR. The ac-9 data were provided by E. Boss and J. R. V. Zaneveld. C. H. Mazel, C. Stephens, and R. Zimmerman all provided bottom reflectance spectra from the LSI area.

\section{References and Notes}

1. Z. P. Lee and K. L. Carder, "Effects of spectral-band number on retrievals of water column and bottom properties from oceancolor data," Appl. Opt. 41, 2191-2201 (2002).

2. E. J. Hochberg and M. J. Atkinson, "Spectral discrimination of coral reef benthic communities," Coral Reefs 19, 164-171 (2000).

3. S. Andréfouët, C. Payri, E. J. Hochberg, L. M. Che, and M. J. Atkinson, "Airborne hyperspectral detection of microbial mat pigmentation in Rangiroa atoll (French Polynesia)," Limnol. Oceanogr. 48, 426-430 (2003).

4. E. Louchard, R. P. Reid, F. C. Stephens, C. O. Davis, R. A. Leathers, T. V. Downes, and R. A. Maffione, "Derivative analysis of absorption features in hyperspectral remote sensing data of carbonate sediments," Opt. Express 10, 1573-1584 (2002).

5. H. M. Dierssen, R. C. Zimmerman, R. A. Leathers, T. V. Downes, and C. O. Davis, "Ocean color remote sensing of seagrass and bathymetry in the Bahamas Banks by highresolution airborne imagery," Limnol. Oceanogr. 48, 444-455 (2003).

6. E. Louchard, R. P. Reid, F. C. Stephens, C. O. Davis, R. A. Leathers, and T. V. Downes, "Optical remote sensing of benthic habitats and bathymetry in coastal environments at Lee Stocking Island, Bahamas: a comparative spectral classification approach,” Limnol. Oceanogr. 48, 511-521 (2003). 
7. J. C. Sandage and R. J. Holyer, "Coastal bathymetry from hyperspectral observations of water radiance," Remote Sens. Environ. 65, 341-352 (1998).

8. J. M. Melack and M. Gastil, "Airborne remote sensing of chlorophyll distributions in Mono Lake, California," Hydrobiologia 466, 31-38 (2001).

9. Z. P. Lee, K. L. Carder, R. F. Chen, and T. G. Peacock, "Properties of the water column and bottom derived from Airborne Visible Infrared Imaging Spectromenter (AVIRIS) data," J. Geophys. Res. 106C, 11639-11651 (2001).

10. C. D. Mobley, Light and Water (Academic, 1994), http: //www.hydrolight.info.

11. F. A. Kruse, A. B. Lefkoff, J. W. Boardman, K. B. Heidebrecht, A. T. Shapiro, P. J. Brloon, and A. F. H. Goetz, "The spectral image processing system (SIPS)—interactive visualization and analysis of imaging spectrometer data," Remote Sens. Environ. 44, 145-163 (1993).

12. C. O. Davis, J. Bowles, R. A. Leathers, D. Korwan, T. V. Downes, W. A. Snyder, W. J. Rhea, W. Chen, J. Fisher, W. P. Bissett, and R. A. Reisse, "Ocean PHILLS hyperspectral imager: design, characterization, and calibration," Opt. Express 10, 210-221 (2002).

13. M. J. Montes, B.-C. Gao, and C. O. Davis, "A new algorithm for atmospheric correction of hyperspectral remote sensing data," in Geo-Spatial Image and Data Exploitation II, W. E. Roper, ed., Proc. SPIE 4383, 23-30 (2001).

14. B.-C. Gao, M. J. Montes, Z. Ahmad, and C. O. Davis, "Atmospheric correction algorithm for hyperspectral remote sensing of ocean color from space," Appl. Opt. 39, 887-896 (2000).

15. E. P. Shettle and R. W. Fenn, "Models for the aerosols of the lower atmosphere and the effects of humidity variations on their optical properties," Tech. Rep. AFGL-TR-79-0214 (U.S. Air Force Geophysics Laboratory, Hanscom Air Force Base, Mass., 1979).

16. R. A. Leathers, T. V. Downes, W. A. Snyder, J. H. Bowles, C. O. Davis, M. E. Kappus, W. Chen, D. Korwan, M. J. Montes, W. J. Rhea, and M. E. Carney, "Ocean PHILLS data collection and processing: May 2000 deployment, Lee Stocking Island, Bahamas," Formal Rep. NRL/FR/7212-02-10,010 (U.S. Naval Research Laboratory, Washington, D.C., 2002).

17. Hyper-TSRB is a product of Satlantic, Inc., http://www. satlantic.com.
18. D. D. R. Kohler, "An evaluation of a derivative based hyperspectral bathymetric algorithm," Ph.D. dissertation (Cornell University Ithaca, N.Y, 2001).

19. Interactive Display Language is a product of Research Systems Inc., http://www.rsinc.com.

20. The ac-9 is a product of WETLabs, Inc., http://www. wetlabs.com.

21. E. Boss and J. R. V. Zaneveld, "The effect of bottom substrate on inherent optical properties: evidence of biogeochemical processes," Limnol. Oceanogr. 48, 346-354 (2003).

22. R. Gonzalez and G. P. Eberli, "Sediment transport and sedimentary structures in a carbonate tidal inlet; Lee Stocking Island, Exuma Islands, Bahamas," Sedimentology 44, 10151030 (1997).

23. C. H. Mazel, "Diver-operated instrument for in situ measurement of spectral fluorescence and reflectance of benthic marine organisms and substrates," Opt. Eng. 36, 2612-2617 (1997).

24. C. H. Mazel and E. Fuchs, "Contribution of fluorescence to the spectral signature and perceived color of corals," Limnol. Oceanogr. 48, 390-401 (2003).

25. F. C. Stephens, E. M. Louchard, R. P. Reid, and R. A. Maffione, "Effects of microalgal communities on reflectance spectra of carbonate sediments in subtidal optically shallow marine environments," Limnol. Oceanogr. 48, 535-546 (2003).

26. A. W. Decho, T. Kawaguchi, M. A. Allison, E. M. Louchard, R. P. Reid, F. C. Stephens, K. J. Voss, R. A. Wheatcroft, and B. B. Taylor, "Sediment properties influencing upwelling spectral reflectance signatures: the 'biofilm gel effect', Limnol. Oceanogr. 48, 431-443 (2003).

27. L. A. Drake, F. C. Dobbs, and R. C. Zimmerman, "Effects of epiphyte load on optical properties and photosynthetic potential of the seagrasses Thalassia testudinum Banks ex König and Zostera marina L.," Limnol. Oceanogr. 48, 456-463 (2003).

28. O. Ulloa, S. Sathyendranath, and T. Platt, "Effect of the particle-size distribution on the backscattering ratio in seawater," Appl. Opt. 33, 7070-7077 (1994).

29. HydroScat-6 is a product of HOBILabs, Inc., http://www. hobilabs.com.

30. C. D. Mobley, L. K. Sundman, and E. Boss, "Phase function effects on oceanic light fields," Appl. Opt. 41, 1035-1050 (2002). 